Florida International University FIU Digital Commons

8-12-1999

\title{
A study of response surface in simulation of emergency room systems
}

Daisy Correa

Florida International University

DOI: $10.25148 /$ etd.FI14061522

Follow this and additional works at: https://digitalcommons.fiu.edu/etd

Part of the Engineering Commons

\section{Recommended Citation}

Correa, Daisy, "A study of response surface in simulation of emergency room systems" (1999). FIU Electronic Theses and Dissertations. 2642.

https://digitalcommons.fiu.edu/etd/2642 


\section{FLORIDA INTERNATIONAL UNIVERSITY}

Miami, Florida

\section{A STUDY OF RESPONSE SURFACE IN SIMULATION OF EMERGENCY ROOM SYSTEMS}

A thesis submitted in partial fulfillment of the

requirements for the degree of

MASTER OF SCIENCE

in

INDUSTRIAL ENGINEERING

by

Daisy Correa

1999 
To: Dean Gordon Hopkins

College of Engineering

This thesis, written by Daisy Correa, and entitled A Study of Response Surface in Simulation of Emergency Room Systems, having been approved in respect to style and intellectual content, is referred to you for judgment.

We have read this thesis and recommend that it be approved.

Dr. Shih-Ming Lee

Dr. Ronald Giachetti

Dr. Martha A. Centeno, Major Professor

Date of Defense: August 12, 1999

The thesis of Daisy Correa is approved.

Dr. Gordon Hopkins

Dean of the College of Engineering

Dean Richard Campbell

Division of Graduate Studies

Florida International University, 1999 
CCOPYRIGHT 1999 by Daisy Correa

All rights reserved. 


\section{DEDICATION}

To my loving parents, Emilio and Lucrecia Correa, without the support and encouragement I would have not been able to complete this thesis. To my brother and my sister for always believing in me and pushing to do my best. I love you all very much! 


\section{ACKNOWLEDGMENTS}

I would like to take this opportunity to thank those people who helped me through the many years of study at F.I.U. Special thanks to my committee members for their contributions and patience during my thesis work. I would also like to thank National Aeronautics and Space Administration (NASA), specifically Kennedy Space Center, for providing me the opportunity to complete my work with the assistance of the grant NAG010-0212.

To Dr. Centeno, my major professor, whose perseverance and dedication supported my efforts to the achievement of this work- thank you so much for encouraging me and having the confidence in me throughout my college career.

Additionally, I want to thank family and friends who have stood beside me during this stage of my life. Special thanks to M. Florencia Reyes, Adriana M. Alvarez, and to the many other people that provided support to me during this process. Also a special thanks to Nancy Urbina and Madlyn Downs whose invaluable assistance assured the successful completion of my degree. 
ABSTRACT OF THE THESIS

A STUDY OF RESPONSE SURFACE IN SIMULATION OF EMERGENCY ROOM

SYSTEMS

by

\section{Daisy Correa}

Florida International University, 1999

Miami, Florida

Professor Martha A. Centeno, Major Professor

The purpose of this research was to characterize a response surface with respect to the changes made to the input variables of an emergency room system. Response Surface Methodology (RSM) was used to identify the behavior of the response variable with respect to the changes made to the input variable.

Several factors were examined for relevancy and significance for the purpose of experimentation. The findings of this research revealed that one factor (nurses) was very significant to the performance measures (time in the system). However, the interaction between the other factors also played an important role. It was determined that a linear regression is not useful in predicting the assessed value of time in the system in emergency rooms. Non-linear models need to be explored. A series of production rules were derived. These production rules can be used in a variety of situations where a decision on how to modify model inputs needs to be made. 


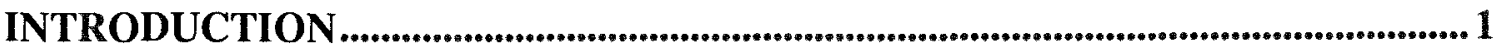

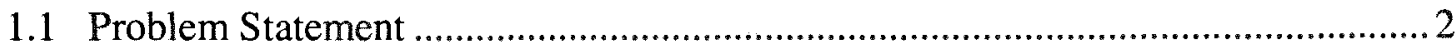

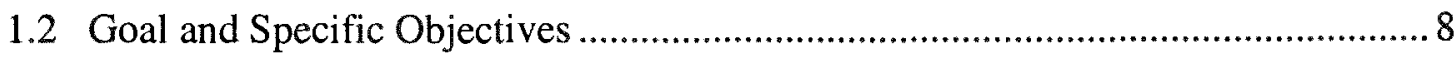

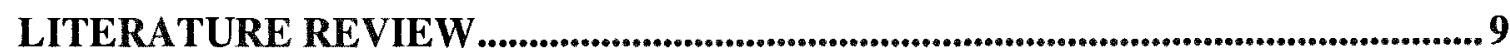

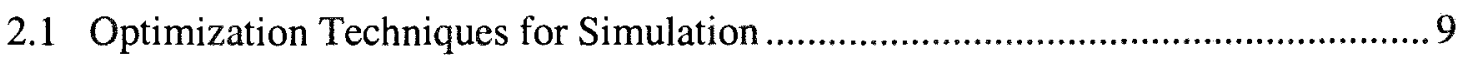

2.2 Simulation for Modeling ER Systems .............................................................. 16

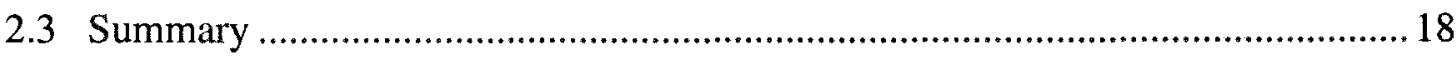

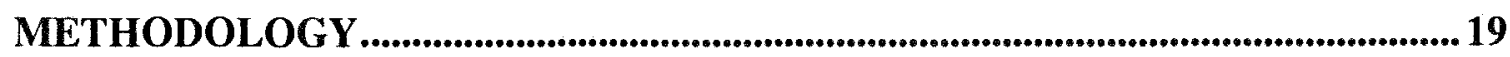

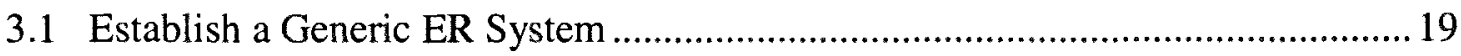

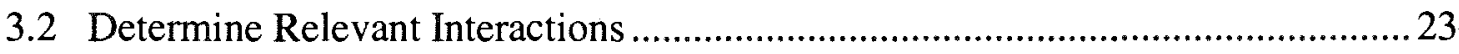

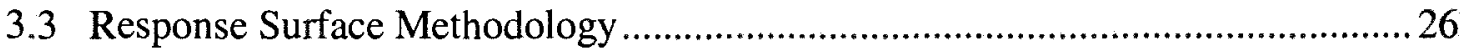

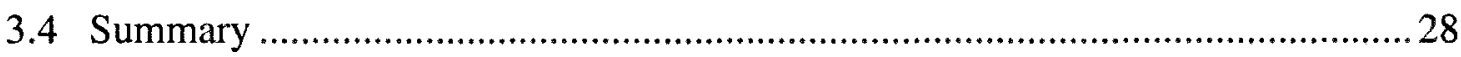

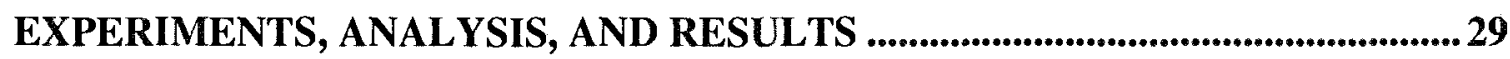

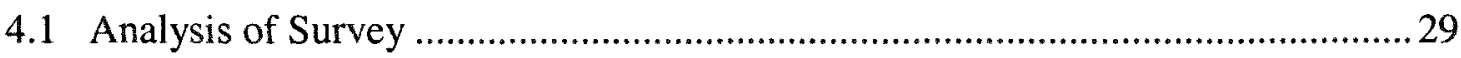

4.2 A Generic Simulation Model of Class 2 ER Systems .............................................37

4.3 Determining Relevant Interactions....................................................................4

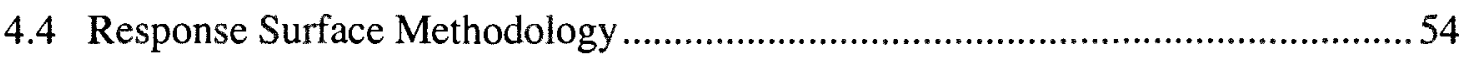

CONCLUSIONS AND FUTURE WORK .......................................................................73

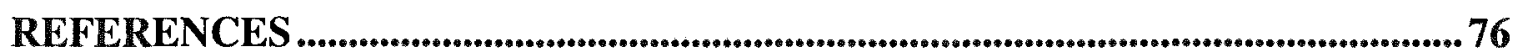

OTHER RELEVANT LITERATURE USED ..........................................................8

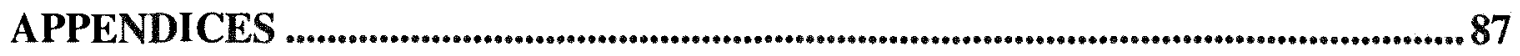




\section{LIST OF TABLES}

TABLE

PAGE

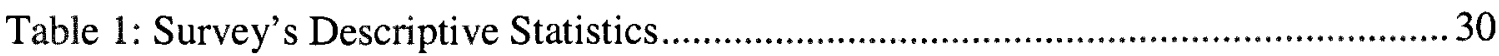

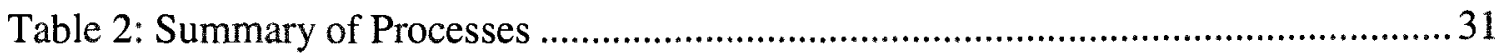

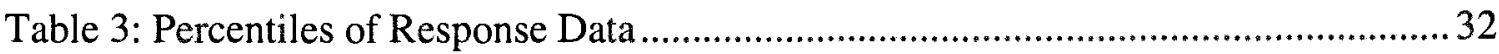

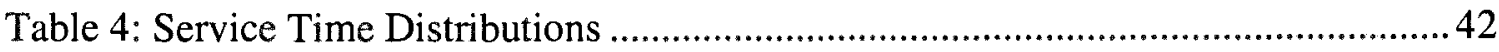

Table 5: Fractional Factorial Experiments ..................................................................... 44

Table 6: Results for Each Experiment - Time in the System ..........................................45

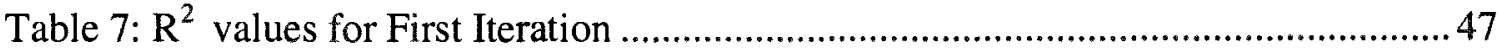

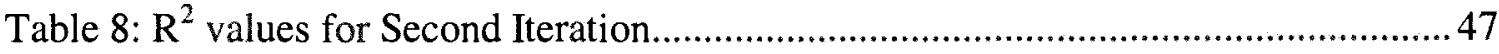

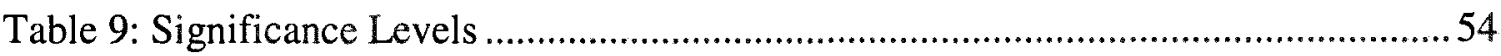

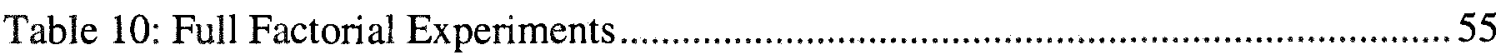

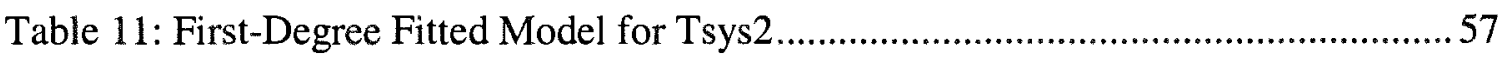

Table 12: Rules to change Nurses for Tsys 2 ..........................................................59

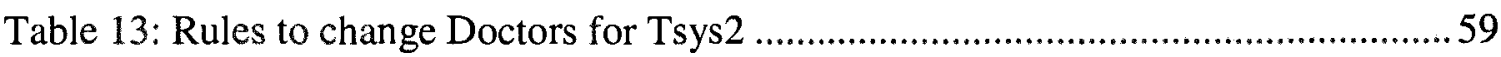

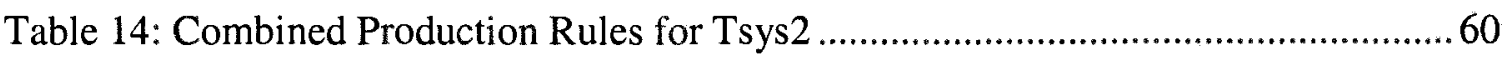

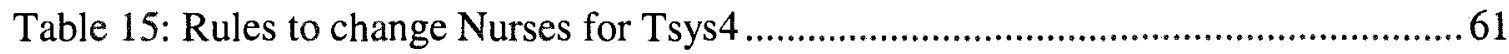

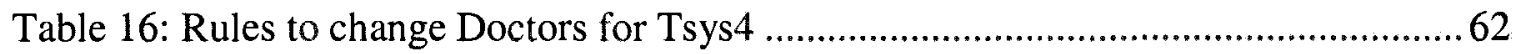

Table 17: Combined Production Rules for Tsys4 ......................................................62

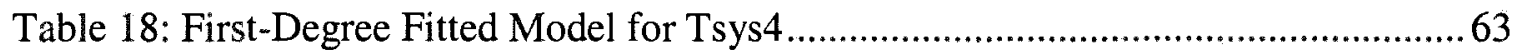

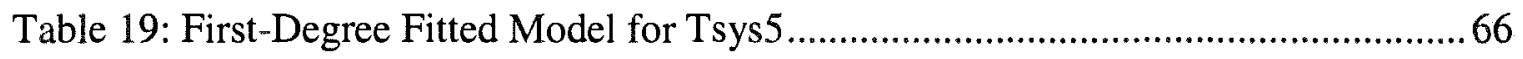




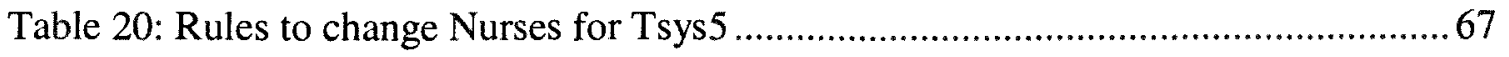

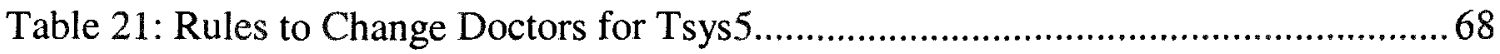

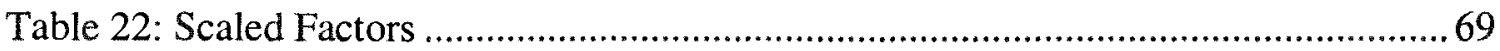




\section{LIST OF FIGURES}

FIGURE

PAGE

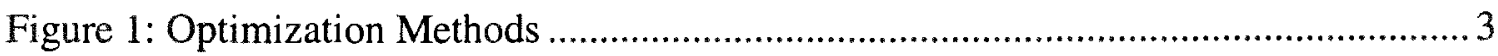

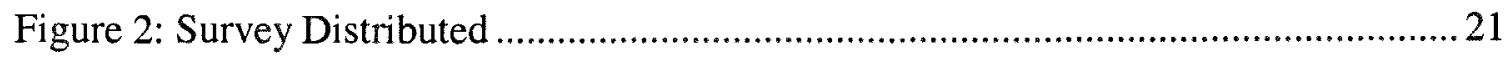

Figure 3: Combined ER Patient Flows......................................................................... 34

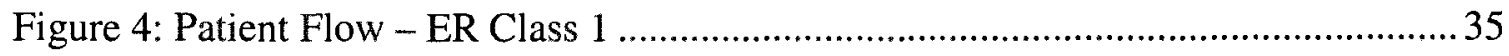

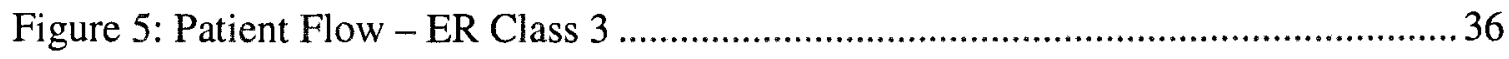

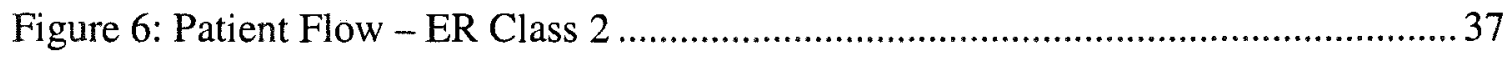

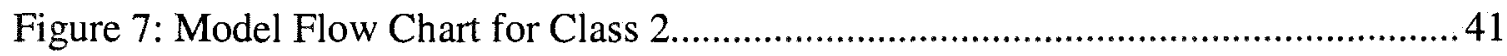

Figure 8: Regression Line to Identify Influential Factor ..................................................46

Figure 9: Nurses vs. Tsys4 Regression Line ................................................................... 49

Figure 10: Nurses vs. Tsys5 Regression Line .............................................................. 49

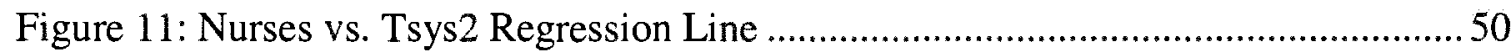

Figure 12: Doctors vs. Tsys2 Regression Line ........................................................... 50

Figure 13: Regular Bed vs. Tsys1 Regression Line ...................................................51

Figure 14: Regular Bed vs. Tsys3 Regression Line ….................................................5 51

Figure 15: Regular Bed vs. Tsys4 Regression Line ...................................................52

Figure 16: Regular Bed vs. Tsys5 Regression Line …..............................................52

Figure 17: Three Views of the (n, d, Tsys2) Relationship ............................................56

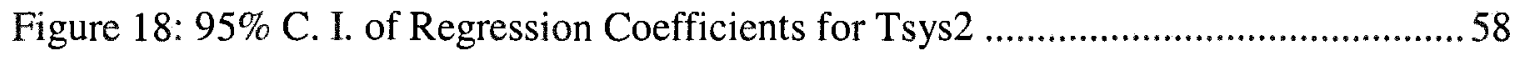

Figure 19: Three Views of the (n, d, Tsys4) Relationship .............................................61 
Figure 20: 95\% C.I. of Regression Coefficients for Tsys 4 .64

Figure 21: Three Views of the (n, d, Tsys5) Relationship ...............................................65

Figure 22: 95\% C.I. of Regression Coefficients for Tsys5 ……....................................6 67

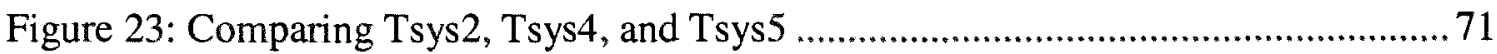

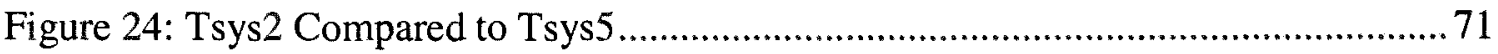

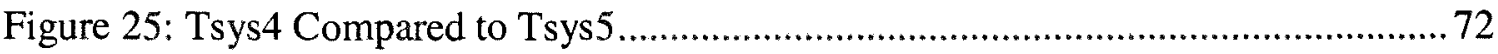




\section{CHAPTER 1:}

\section{INTRODUCTION ${ }^{1}$}

Simulation is a tool that represents a real-world system, generates data, but it does not optimize. Currently, simulation results are optimized either by using various mathematical techniques after the simulation model has been executed or by iterating through a finite set of inputs, observing the system's response to these inputs, and then selecting the "optimum". Of these two approaches, the former actually gives the true optimum, whereas the latter merely gives an answer that is satisfactory to the user. However, it has been difficult to integrate simulation modeling and mathematical optimization; nonetheless a lot of efforts have been devoted to it. For instance, Fu and Healy (1997) combined optimization and simulation by using retrospective methods and gradient-based methods. They found that the combination of both techniques modified would enables the search of an optimal answer in inventory systems. Another example is the work of Hsu and Nelson (1988). They used a technique called multiple comparison with the best to find an optimal design for inventory systems and machine-repair systems. However, since the method only works with a finite number of system designs, it yields only a sub-optimal answer.

Hospitals have gained substantially with the use of simulation modeling. Durham Regional Hospital was able to show that they would save about $\$ 150 \mathrm{~K}$ annually if they

\footnotetext{
${ }^{1}$ Funded under NASA Grant NAG010-0212
} 
implement the configuration found using simulation. St. Luke Hospital was looking to decrease the length of stay in the emergency rooms (ER). A simulation model was used to find a configuration that would decrease it by as much as 40 percent. Other hospitals also used simulation modeling to improve emergency rooms and maintain the best quality care for the patients. Despite these successes, few efforts have attempted to use optimization in the simulation of ER systems.

The purpose of this research effort was to study the response surface of emergency room systems with respect to changes to the input variables. By gaining an understanding of the input and output relationships in ER systems, it was expected that heuristics could readily be developed to optimize the decision variables.

A generic model was determined by ways of surveys and interviews. Therefore, to experiment with this generic model a simulation model was developed using ARENA. Once the model was validated and verified, several experiments were ran. From these experiments and with the use of RSM, the most significant input variables, other wise known as factors, were determined. Additionally, from the use of RSM response surfaces were graphed in which the production rules were derived.

\subsection{Problem Statement}

Simulation models are executed for a specified amount of time or for a specified number of units. A simulation model is given a set of inputs, so that it can generate data to make inferences about the system's performance. Traditional simulation modeling 
(TSM) does not optimize the collected data although a system analyst is typically concerned with establishing the optimal conditions to operate the system. In general, optimization seeks values for a set of decision variables that would maximize or minimize an objective function, subject to some constraints (Rardin, 1998). Thus, it is natural that researchers have strived to merge the power and flexibility of simulation with the mathematical sharpness of optimization. The ability to run a simulation model, which will produce optimal answers for a set of decision variables, is highly desirable.

Several methods and techniques have been explored that would enable simulation modeling to optimize. Figure 1 shows the different optimization methods that have been used for simulation. All these methods have benefited simulation in the search of optimizing the output variables. However, the majority of the methods find "near" optimal solutions.

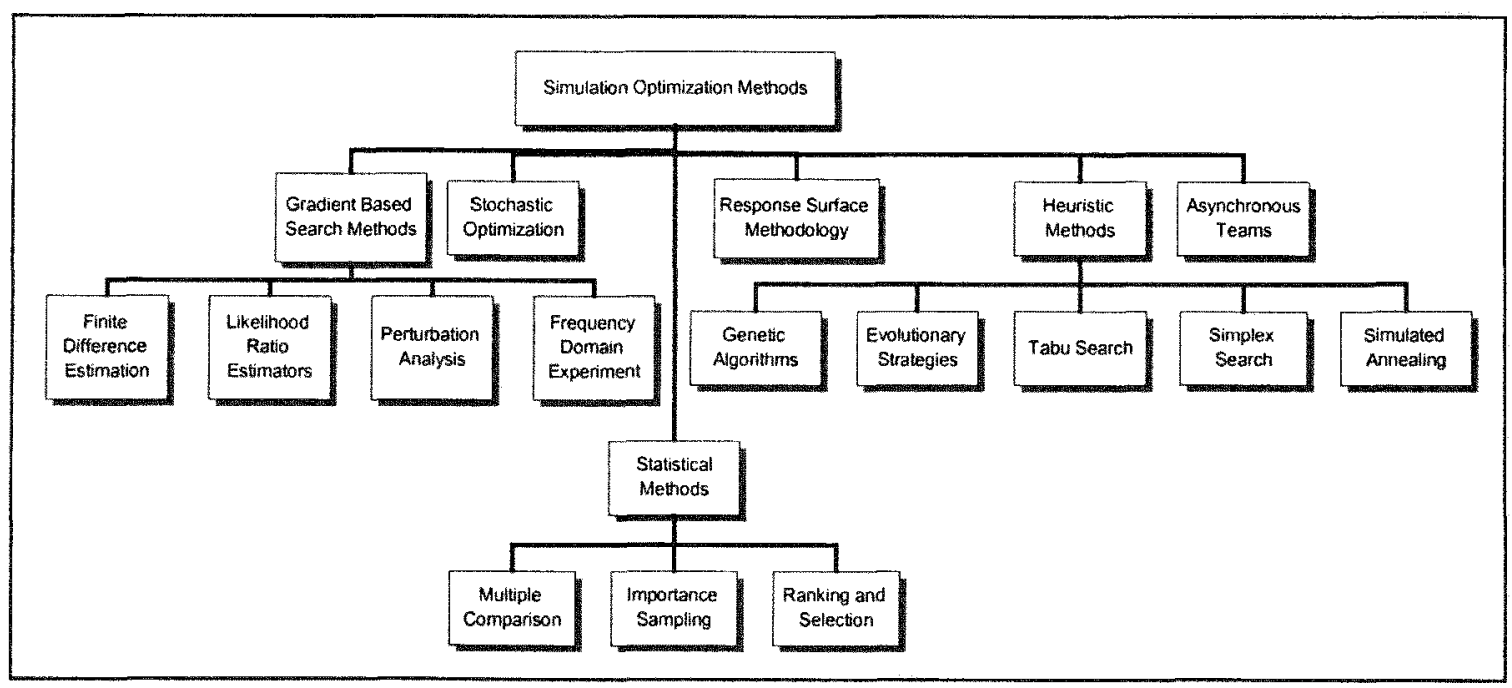

Figure 1: Optimization Methods 
In the category of Gradient-based search methods, several techniques have been used, including finite difference and perturbation analysis. Finite Difference (FD) estimation requires the derivatives of output variables to estimate the gradient. To gain reliability of the gradient multiple observations are needed at the expense of computational effort. The idea behind perturbation analysis (PA) is that it is capable of producing all the necessary partial derivatives in one simulation run. Frequency domain experimentation (FDE) performs its analysis during one long simulation run; however, it oscillates the value of the parameter according to a sinusoidal function during the simulation execution (Fu, 1994b). Fu and Healy (1997) combined gradient-based search method with a retrospective algorithm to develop a hybrid approach to improve the convergence properties of the gradient scheme and reduce the computational effort of the retrospective approach. Likelihood ratio (LR) method takes the derivative of the expected value of the output variables with respect to the input variables.

Response Surface Method (RSM) is a heuristic that guarantees no success (Kleijnen, 1995). If the number of control variables grows, the effort to find an accurate estimate for the coefficients also increases, hence, the efficiency and the cost would be ill favored. In the first of its two-phase sequence, RSM uses gradient methods to iteratively locate a "best guess" of optimal parameters. To minimize the iterative process a screening procedure is applied to the factors. The downfall of the screening process is that the user may drop a factor that may have been an important one. Therefore, screening from a list of hundreds of factors to narrow the list to a manageable few would be necessary but if done incorrectly, the user may not reach the optimum answer. 
According to Safizadeh (1990), RSM assumes that the user is able to identify, at least approximately, the region of interest as is characterized by the constraints that were defined for the problem.

These techniques (FDE, LR, PA, FD, and RSM) are robust techniques that work well if and only if the underlying assumptions are strictly met. However, satisfying these assumptions is not always an easy task. For instance, FDE and PA require that the modeler have complete knowledge of the simulation model itself to add tracking capabilities. For example, when performing sensitivity analysis using PA, the system can change or be perturbed by in infinitesimal amount. Therefore the modeler will need to know where to add the tracking sequence within the model. In addition, using PA for complex simulation models may not be adequate because it assumes that the perturbation of the decision variable is small, and that it does not alter the order of events during the simulation run. In the case of Fu and Healy's (1997) work, the difficulty they ran into was establishing the initial step size for the search and the update period for the inputs. The major drawback of LR is that estimating the gradient is not always possible, and it requires the differentiation of a probability measure.

The success of these techniques varies depending on the domain of the simulation model. Simulation models are used to represent a great variety of systems, such as computer systems, manufacturing, business, government, ecology and environment, society and behavior, bio-science, and Health Care Facilities (HCF) (Pegden, Shannon, and Sadowski, 1995). In most cases of simulation optimization, what works in one area does not work in another. Consequently, the use of these optimization techniques has 
been confined to a small set of classes of systems. Researchers are still looking for more general optimization algorithms or heuristics, so that a larger set of systems may be optimized.

A class of systems of significant interest is health care systems. In fact, the last decade (1990's) has seen a lot of discussion on the high cost of health care. HCF have been forced to closely study their revenues and expenses, so that they can continue to deliver quality service at a lower cost. Simulation models have proven to be an asset in the study, modeling, and analysis of ER facilities in a HCF (Lowery, 1996). In fact, modeling ER systems has resulted many times in significant cost reduction and in better perceived quality. For instance, Lowder (1997) reported that for Durham Regional Hospital a $\$ 150,000$ annual saving was obtained after a thorough study was done. By simulating the addition of a new service area, they were able to reduce the level of staffing and reduce the waiting time per patient.

Other efforts that show the importance of simulation in health care systems include McGuire (1994), Garcia et al. (1995), and Kirtland et al. (1995). McGuire (1994) addresses this issue of customer satisfaction by applying simulation to reduce the length of stay for patients within the ER. He states that the significant percentage of a hospital's total admission arrive through the ER; thus, increasing customer satisfaction would increase the number of annual visits. His study revealed that the patients are less willing to accept long waits in any department, particularly in the ER.

Baptist Health Systems (1998) statistics for its 1996 fiscal year state that 124,100 of its patients entered the emergency room. Comparing this to the number of admissions 
to the hospital (approximately 51,500 ), it can be observed that more than twice as many patients interact with the ER than with other systems in the HCF. With such a large amount of patients in ER rooms, it is only natural that improvements should be sought in ER's.

Garcia et al. (1995) studied the ER at Mercy Hospital to reduce the time in the system for non-critical patients with the assistance of simulation modeling. They determined a reduction of 25 percent in the length of stay for these non-critical patients without jeopardizing the lives of the critical patients. Kirtland et al. (1995) also found simulation useful in the reduction of patient waiting times in the ER. The project considered 11 alternatives of which the impact of the changes from the top three would reduce the patient turnaround time by 38 minutes. A high standard of quality care, and a reduced time in ER should result in more satisfied customers (patients); hence, it should generate a greater income for the hospital.

These efforts have shown that simulation modeling is indeed a valuable tool for the analysis of ERs. However, ER managers still have to engage in iterative, off-line output analysis to determine the "optimal performance" levels. To help them, several companies have attempted to combine optimization and simulation into one package. For instance, ProModel Corporation added SimRunner Optimization to their PROMODEL software. It provides the best answer under a sophisticated "what-if" analysis in a short amount of time. However, ProModel was specifically designed for all types of manufacturing systems ranging from small job shops and machining cells to large mass production, flexible manufacturing systems, and supply chain systems (Benson, 1997). 
Although ProModel could be used to model ER facilities, it would require a significant learning for ER managers. ProModel Corporation realized this drawback and developed MedModel. This new software grants the ability to model complex interdependencies found in ERs and provides ease of use. MedModel is also capable of using SimRunner. SimRunner gives psuedo optimal answers in the sense that it merely provides satisfactory responses for the user. In this sense, SimRunner still uses an iterative approach within its genetic algorithm scheme.

Despite SimRunner's limited success, there still is significant room for improvement. A better understanding of the response surface of ER systems would lead to better optimization approaches.

\subsection{GOAL AND SPECIFIC OBJECTIVES}

The goal of this effort was to characterize the response surface, with respect to the changes made to the input variables, of an emergency room system. In other words, this is a study of how several measures of performance reacted to variation in the controllable inputs.

By understanding the behavior of response variables, it would be possible to establish relationships between inputs and outputs. The methodology of this effort is described in Chapter 3. The experiments, experimental model, and results are described in Chapter 4. 


\section{CHAPTER 2:}

\section{LITERATURE REVIEW}

This chapter provides a review of some of the relevant works on simulation optimization. Researchers have tried to use many different techniques to optimize simulation outputs; however, the literature reveals that in many instances the technique is applicable only to a very narrow domain. Most of the published efforts have focused on manufacturing systems. Only a handful of these efforts have addressed simulation optimization for ER systems. This review classifies the various efforts by methods or techniques, with a historical perspective.

\subsection{OPTIMIZATION TECHNIQUES FOR SimUlation}

Several methods and techniques have been explored that would enable simulation modeling to optimize.

Figure 1 shows the different optimization methods that have been used for simulation.

The gradient method has been considered successful based on its reliability and efficiency. The methods within gradient search are finite differences, likelihood ratio, frequency domain, and perturbation analysis. In finite differences, the simulation model is run several times to obtain a secant as an estimate to the gradient (Azadivar, 1992). In the likelihood ratio method, the gradient of the simulation output variable with respect to 
its input variables is estimated. The way this method operates is to differentiate the essential probability measure of the system. In Perturbation analysis, all gradients of the objective function are estimated from a single simulation run. Frequency domain analysis is one in which selected input parameters are oscillated sinusoidally at different frequencies during one long simulation run (Carson and Maria, 1997). It was initially proposed as a screening tool to identify important factors from a large set of parameters, consequently providing a more efficient method over traditional factorial design computations.

Methods in the area of stochastic optimization include the Robbins-Monro algorithm and the Kiefer-Wolfowitz algorithm (Fu, 1994a). These methods only find a local optimum from the iterative procedures of estimating the gradient of the performance measures with respect to the parameter.

Five types of heuristic methods are found in the field of direct search method, genetic algorithms, evolutionary strategies, Tabu search, simplex search, and simulated annealing. Genetic algorithm (GA) is analogous to the biological evolution. This is due to the fact that variables are represented as genes on a chromosome. More specifically, an offspring's genetic DNA is a combination of both parents' DNA. The chance of survival for the offspring increases when the combination of the parents' traits generates new traits within the offspring. The difference between GA and other optimization techniques such as Gradient Strategies is that GA provides a robust search strategy that does not require continuity and differentiability for the problem domain (Joshi et al., 1996). Amaral et al. (1992) used genetic algorithms to find "good solutions" for a Combinatorial Optimization 
Problem (COP). Yunker and Tew (1994) used GA to compare pattern search and RSM search. Tompkins and Azadivar (1995) also used GA to develop a simulationoptimization method that works on qualitative variables. They combined GA with object-oriented simulation, in a way in which genetic algorithms recommend system designs. These designs get converted into simulation models to generate data that guide the algorithm in its selection of future designs.

An evolutionary strategy (ES) is similar to genetic algorithms in the sense that they mock the principles of the natural evolution as a method to optimize (Carson and Maria, 1997). In the method called Tabu search (TS), attributes are defined to restrict the process from choosing certain solution that may resemble solutions in the past. This feature was designed to help avoid being stuck in local minimum.

In the next method called the simplex search, the process starts with an $n$ dimensional space. The search continues to first guess at the $n+1$ points from the solution space. Proceeds to drop the worst point from the solution space and adding new points that reflect away from the point just dropped.

The last of the heuristic approaches is simulated annealing (SA). The goal of SA is to obtain a global optimum by using the hill climbing technique. The name simulated annealing comes from the annealing process of slowly cooling metals to improve its strength. In analogous to the cooling process, the settings of the variable being evaluated are perturbed or changed to see if the outcome is better than the previous. However, SA requires more objective function evaluations than other optimization techniques (Shaffer, 1999). 
An asynchronous team (A-Team) is a process that involves the combination of several problem-solving strategies. Talukdar (1998) explains that A-Teams are a way of organizing large numbers of very different agents to solve a problem. These agents are independent of each other and can work in parallel all the time. Although the agents may not "speak" the same language, a few rules are used to warrant a speedy convergence of their efforts to find good solutions.

Supporting statistical optimization techniques are multiple comparison, importance sampling, and ranking and selection. By way of multiple comparison, the idea is to make inferences on the performance measure of interest through confidence intervals (Fu, 1994b). Under multiple comparison, there are three different categories. The first procedure is known as "brute force" paired-t, Bonferroni, all-pair-wise comparison approach that works particularly well when common random numbers are applied. The second is called an all-pair-wise multiple comparison (MCA). This procedure requires equal variances and independence. The third is called multiple comparison with the best (MCB) (Fu, 1994a). The idea behind MCB is the reduction of comparisons needed to pick only the best. Importance sampling is a variance reduction technique in Monte Carlo estimation, which effectively achieves notable speed-ups in simulation involving rare events. The idea behind this method is the assignment of different probability distribution for rare event, such as within a failure analysis project and then running the new simulation model to note the new observations. Ranking and selection contains two procedures that need to be considered for the performance of optimization. The first is called indifference zone, which involves selecting the best 
system design that is within some pre-specified difference from the true optimum. The second is called subset selection, which is employed when a subset of system designs is selected with the best system design within it. These procedures work well when the parameter set is finite. However, the disadvantage of this procedure in the requirement of independence over competing designs.

Some of the more recent work has been in retrospective simulation. Healy and Schruben (1991) explain that in the real world one can not make correct decisions after the fact. Therefore, the idea behind retrospective simulation is to solve a deterministic optimization problem with the awareness of the uncertainties as though these outcomes were known in advance. Chen and Schmeiser (1994) developed a subclass of retrospective algorithms called retrospective approximation. Healy (1994) experimented with the technique and produced a variant which addresses conditions that will make more sense to define the "best" solution as one that is most likely to present desirable results.

Several efforts pertain to multidisciplinary analysis of systems. Multidisciplinary analysis is where one design space is dependent of the design space of other design spaces. Evans et al. (1991) discussed the unique difficulties within this problem area along with the important characteristics, and discussed a way that these problem characteristics would affect the choice of a particular technique. They provide a framework for multi-criteria optimization of simulation models. Therefore, based on the various characteristics of a problem, a particular optimization technique is suggested. Evans and Mollaghasemi (1994) introduce simulation optimization for multi-criteria 
design of manufacturing systems. Together they describe an interactive methodology for multiple response optimization of simulation models. The approach taken is unlike other approaches in the sense that it does not seek to first find the response surface equation and later optimize them; instead, they use a technique called STEP method to arrive at a best trade-off solution. Lee et al. (1996) developed an effective algorithm using RSM and testing it on a turning operation. Their research is developed with the use of weights and trade off to find the optimum cutting condition for the turning process with minimum processing time and good surface texture.

A more common approach to simulation optimization is response surface methods (RSM). RSM fit a series of regression models of the response variables and optimizes the resulting regression function. Some authors distinguish RSM as having two different categories, meta-models and sequential procedures. However, most of the literature talks mostly about sequential procedures. It has been identified that there is little benefit from applying meta-models because of its large computational effort. Therefore, RSM is defined by applying the second category. The process begins with a first order function to which the steepest ascent/descent search methods are applied. As the locality of the optimal is approached, higher order functions are utilized. Kleijnen (1995) suggests that before RSM is applied a technique called sequential bifurcation should be performed. Sequential bifurcation is a screening process that searches for important factors from a set of many factors. From this short list of important factors, RSM is used to approximate the behavior of the simulation model. 
Korngold and Gabriele (1997) utilized RSM to build local response surfaces to efficiently optimize multidisciplinary systems with discrete variables. The purpose of using RSM for their research was to predict the response at points where observations have not been taken previously.

Hood and Welch (1993) enumerate a couple of examples. One example was the use of RSM in a semiconductor manufacturing line, which concerns two variables. The "arrival" of an interruption and the length of the interruption. An interruption in this semiconductor facility problem is either a tool set up, preventive maintenance, and repair of failures. However, in this example, only the setup interruption will be evaluated. The second example was an extension of the first. They considered all three of the interruptions, where the problem would have a total of six parameters (arrivals and service times). This example was to show the flexibility RSM. The technique may be applied to a system and evaluate the parameters that are of interest to the analyst.

Gaston and Walton (1994) also applied RSM to a semiconductor facility. They realized that the application of RSM with simulation reduces the time spent if the experiment was evaluated changing one variable at a time.

Boning and Mozumder (1994) used RSM to develop a tool called DOE/Opt. The purpose of this tool was to integrate the techniques of DOE, regression analysis, and optimization. The use of this tool was to support manufacturing processes in the field of integrated circuit technology. 
Chiu et al. (1994) employed RSM to explore their multi-layered neural network designed for time series forecasting. They found that with RSM the neural network provided a more accurate prediction of the response.

\subsection{SIMULATION FOR MODELING ER SYSTEMS}

Several improvements have been made using simulation in the ER. In general, the research has been concentrated in reducing the time in the system for the patients to target customer satisfaction. For instance, McGuire (1994) describes a team of the SunHealth Alliance hospital's ER using simulation technology to find a solution to reduce the length of stay. With the model once built, the team tested 5 different alternatives and found that each alternative had its own type of improvement. Some modifications were made to these alternatives to combine the best of the changes. This combination of the alternatives was suggested to the management of the ER. Freedman (1994) studied the effects of policy and resource allocation changes on the average length of stay. Using simulation as the tool to analyzing the problems within the hospitals, Freedman was able to identify that with the implementation of a computerized information system for better communication between the housekeeping staff and the hospital's medical staff, it would reduce the time patients wait to get admitted to the hospital.

Another hospital that employed simulation to better analyze the quality of patient care and the use of resources was Mercy Hospital. Pallin and Kittell (1992) evaluated a fast track alternative where the patient would be referred to their private medical doctor 
instead of having them return for a second visit to the hospital. They were able to identify savings of 50 percent in terms of staffing and resources as a result of the simulation model without penalizing the care of the patients.

To further collaborate to the search of increasing the "bottom line" by reducing cost and increasing customer satisfaction is Manansang and Heim (1996). In an approach to cost savings in the ER, they investigated the coordination of multiple resource allocation and resource sharing dependencies in the University of Washington Medical Center. The primary concern for this research was the utilization of professionals and the technological resources providing support to them. With the development of a prototype of a simulation-based decision support system they were able to conduct "what-if" experiments so that the hospital can work more efficiently and patients can be provided with better service.

Durham Region Hospital was very involved in reengineering and redesign projects (Lowder, 1997). In this case they used simulation to model a new express service area for the hospital. The results showed that the proposed staffing levels could be reduced, the model gave the hospital the ability to avoid bottlenecks in the radiology department, and that the new express service should be closed during the weekends. This evidently led to a cost saving of about $\$ 150,000$.

However, most of the literature found in this review has taken the iterative process to find their solutions. These articles find answers to where customers are satisfied and even the hospitals gain substantial savings. The iterative "what-if's" of simulation can do this for the user. However, optimization methodology can have a more significant impact 
on the hospital with the use of simulation.

\subsection{SUMMARY}

In this chapter, several techniques in simulation optimization were discussed in the environment of manufacturing processes. However, the application of them in an ER system has been performed very seldom. Nevertheless, many improvements were made with the use of simulation, the utilization of optimization techniques that does not require an iterative process may reduce the time spent analyzing the output. 


\section{CHAPTER 3:}

\section{METHODOLOGY}

This chapter describes the several steps taken to achieve the research goal of this effort. It also explains the rationale for having chosen such steps, methods, and techniques. These steps will be explained further in this chapter as follows:

1. Establish a generic ER simulation model.

2. Build a simulation model.

3. Determine relevant interactions among the inputs with respect to the outputs, using Design of Experiments (DOE).

4. Graphical analysis of the response surface.

5. Analysis of the response surface using RSM.

For a detailed discussion of the various analysis and results, see Chapter 4.

\subsection{ESTABLISH a GENERIC ER SYSTEM}

The main goal of this research effort was to understand the behavior of the measures of performance as the inputs change. Hence, the goal assumes implicitly that a model of a system would have to be developed, so that appropriate experimentation could be done. Consequently, it was necessary to answer the following questions: which ER system should be used for the model? This question led to other questions, including:

- If ER system "Alpha" is used, will the conclusions drawn be applicable to any 
other ER system?

- If the conclusions drawn by using the ER system "Alpha" can not be generalized, is it possible to devise a generic ER system?

- Is there a single generic ER system?

- Are there several classes of ER systems for which different generic models could be developed?

Before this research could continue, these questions had to be answered. Furthermore, there was a lack of familiarity with the various processes followed in an ER system and their configuration. Hence, a survey was developed to collect data.

A survey was devised and distributed to hospitals around the United States for the purpose of finding similarities among ER systems and to get familiar with the physical configuration, number of resources, and the processes within ER system. The development of the survey was based on work done by Alvarez (1999). Alvarez's survey was useful in the sense of understanding the format and, most importantly, the length of the survey. The length is critical in a survey formulation because hospitals are very careful as to taking time out from helping the sick to answer a long survey. In addition to Alvarez's work, the web was used to gather more information, such as the size of the hospital and some of their resources for the construction of the survey. Several hospitals around the country have web sites that describe their ER system to an extent. Hence, it was possible to acquire enough knowledge about ER operations and their vocabulary. The surveys (Figure 2) were distributed via email and via fax. 


\begin{tabular}{|c|c|}
\hline PHYSICAL CONFIGURATION: & RESOURCES: \\
\hline $\begin{array}{l}\text { 1) How many fast tracks in the ER? } \\
0 \square 1 \square 2 \square 3 \square 4+\square \\
\text { Comment: } \\
\text { How many beds in the fast track? }\end{array}$ & $\begin{array}{l}\text { 6) What is the total number of nurses } \\
\text { that work in the ER? } \\
\square 0-5 \square 6-10 \square 11+ \\
\text { Comment: }\end{array}$ \\
\hline $\begin{array}{l}\text { 2) How many beds in the ER? } \\
\square 0-5 \square 6-10 \square 11-15 \square 16-20 \square 21-25 \square 26+ \\
\text { How many more? }\end{array}$ & $\begin{array}{l}\text { 7) Is there a difference between the } \\
\text { nurses? Meaning are they all RN's? } \\
\text { Yes } \square \text { No } \square \text { explain: }\end{array}$ \\
\hline $\begin{array}{l}\text { 3) How many beds are in the hospital? } \\
\square 0-100 \square 101-150 \square 151-200 \square 201-250 \square 251+ \\
\text { How many more? }\end{array}$ & $\begin{array}{l}\text { 8) What is the number of physicians } \\
\text { dedicated to the ER? } \\
\square 0 \square 1 \square 2 \square 3 \square 4+\end{array}$ \\
\hline $\begin{array}{l}\text { 4) you have private rooms for each patient } \\
\text { when they enter the ER? } \\
\text { Yes } \square \text { No } \square \text { Comment: }\end{array}$ & $\begin{array}{l}\text { 9) Any specialist in the ER? } \\
\text { Yes } \square \text { No } \square\end{array}$ \\
\hline \multirow[t]{2}{*}{$\begin{array}{l}\text { 5) What dedicated auxiliaries does your ER have? } \\
\square \text { x-rays } \square \text { blood analysis Other: }\end{array}$} & $\begin{array}{l}\text { 10) What kind of specialist? } \\
\square \text { Neurology } \square \text { Cardiology } \\
\text { Other }\end{array}$ \\
\hline & $\begin{array}{l}\text { 11) What type of technicians work in } \\
\text { the ER? } \\
\text { Who depend on them? } \\
\text { What type of jobs are performed by } \\
\text { these technicians? }\end{array}$ \\
\hline \multicolumn{2}{|c|}{ PROCESSES: } \\
\hline $\begin{array}{l}\text { 12) How are the patients classified? } \\
\text { For example: type 1: emergent type 2: urgent } \\
\text { type3: non-urgent, etc. Please specify: }\end{array}$ & $\begin{array}{l}\text { 15) Can you briefly describe the flow of } \\
\text { patients when they enter the ER? }\end{array}$ \\
\hline $\begin{array}{l}\text { 13) How many shifts does the ER work have? } \\
1 \square 2 \square \quad 3 \square \quad \text { more }\end{array}$ & \multirow[t]{2}{*}{$\begin{array}{l}\text { If you have any additional comments } \\
\text { please write them below. }\end{array}$} \\
\hline 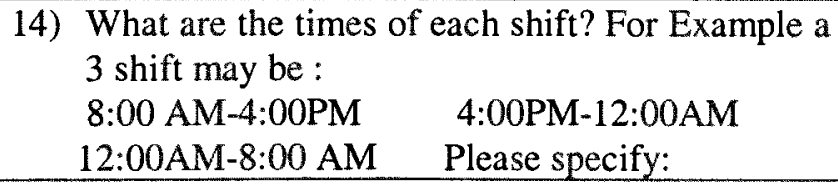 & \\
\hline
\end{tabular}

Figure 2: Survey Distributed 
The survey questions were divided into three sections: physical configuration, resources, and processes. Some of the questions that were asked in the survey were for designing the experiments described in section 4.2. Since there is a possibility of having an infinite amount of alternatives for each factor, questions such as one and two will provide good starting point for the assigning of levels to the factors. These two questions will provide the physical configuration in addition to the ER capacity of the system. Other questions such as three, four, and five, were utilized to make sure that the ER's that were surveyed were about the same size. For example, it was imperative that all the hospitals face the same conditions and situations. An ER that sees 5,000 patients a year is run differently than an ER which sees 80,000 patients. According to the Emergency Nurses Association (ENA) (ENA, 1997), a facility that sees approximately 40,000-50,000 patients a year is to staff an average of 33 registered nurses (RN) in the ER to handle the demand. Some of the other questions on the survey, such as those in the resources section, served as a starting point for building the simulation model.

Once the answers began to arrive, some ER administrators were contacted via email and by telephone because some of the answers were illegible. During these sessions of clarification, additional information was gathered. From the follow up interviews, it was noted that it is possible that a smaller size facility never see what is considered here a "critical" patient. Therefore, the auxiliaries needed to handle critical patient in this facility would not be needed. The purpose of the question also served as redundancy, in case they failed to mention it during the processing section of the survey.

With the surveys that returned, the responses were analyzed to determine if a 
generic ER system existed. From conversation with the ER administrators, and by looking at some of the responses, it seemed that every single ER was different from every other ER. However, by categorizing and tallying each one of the responses, it became clear that there were some commonalties among the responses. The data was closely scrutinized using tallies, charts, and other basic descriptive statistics. To best describe a simulation model of an ER system as generic, it was essential to find if there was a significant amount of processes that fell into the same classification. The processes for each respondent were drawn to visualize similarities and differences. This led to four different classes as discussed in Chapter 4.

Descriptive statistics were used for basic analysis of the survey responses. A fullscale inferential analysis was not possible due to the small size of the sample set. Nonetheless, it was possible to establish appropriate boundaries for some of the input parameters. A detailed analysis of the survey responses is given in Section 4.1.

\subsection{Determine Relevant InTERactions}

In an ER system, many factors may be evaluated under many different levels. These factors include nurses, doctors, beds, configuration, demand rate, service rate, and so forth. All of these factors affect the measures of performance differently. Furthermore, for an experiment that could have at least six factors, with the possibility of each having fifty levels, it would be time consuming to test all the alternatives for each factor and for each possible interaction. In fact, for six factors and fifty levels for each, it 
would be necessary to do approximately fifteen billion experiments. Hence, a question arises: are all the factors significant? Are all the interactions significant? Not every factor may be as significant; not every level of a factor may be relevant. If some of the factors/levels were not significant, it would be possible to reduce the size of the experiment, e.g. from six factors to five and from fifty levels to thirty. If the latter were true the number of experiments would drop from 15 billion to 24 million. Therefore, Designs of Experiments (DOE) was used to identify which factors were significant.

DOE would work with simulation data in the same fashion as it works with other experimental data. In the case of simulation, the factors are the input variables such as the number of nurses, doctors, fast track beds, regular beds, and so on. The levels associated with each of these factors would be the domain of these variables, e.g. 1, 2, 5, etc. For example, nurses (A) can have two levels, e.g. 2 and 4; Doctors (B) can also have two levels, e.g. 1 and 2; and regular beds (C) may also have two levels, e.g. 10, 15. The combination of their different levels will provide eight different treatment designs in the experiment. In simulation terms, the response is the output given for a measure of performance. Hence, one observes how the measure of performance responds to the various settings of $\mathrm{A}, \mathrm{B}$, and $\mathrm{C}$. Each run is considered an experiment. The different set of experiments conducted with the simulation model is called a full experimental design.

In the case of an ER system, there are many factors to consider at many levels; hence, a random balance fractional design was formulated to reduce the experimental space. In a random balance experiment, the researcher establishes before hand how many experiments he or she would like to run. Once this is established, it is simply a matter of 
selecting the most appropriate experiments (Anderson and McLean, 1974). For example, suppose that now $\mathrm{A}$ and $\mathrm{B}$ may have levels in the range of two to five and $\mathrm{C}$ may have 15 levels, such that factor A has 5 levels, factor B has 4 levels, and factor $\mathrm{C}$ has 15 levels.

The total number of treatment combinations in this example would be $5 * 4 * 15=$ 300 experiments. Hence, it would be very time consuming to execute all these experiments. Thus, the researcher may decide to look at only 25 treatment combinations. The method of obtaining the 25 treatment combinations out of the possible 300 by random balance design is as follows:

1. For factor $A$ take a random number between one and five, $R_{1}$.

2. For factor $B$ take a random number between one and four, $R_{2}$.

3. For factor $\mathrm{C}$ take a random number between one and fifteen, $\mathrm{R}_{3}$.

4. Execute the experiment given by the combination $\left(R_{1}, R_{2}, R_{3}\right)$.

5. Repeat 1 to 4 for the other 24 treatment combinations.

For the DOE analysis of this effort, four factors were used at many different levels. These factors are nurses, doctors, fast track beds, and regular beds. A random balance experiment was designed using the random number generation capabilities of Excel.

As the experiments were run and the outputs analyzed, it was noted that a random balance experiment was not going to give a full picture of the surface behavior because it would leave unexplored points on the surface. Hence, the surface would be extrapolated linearly, yielding a flat plane, even in areas where it may not be flat. Consequently, a smaller full factorial experiment was done. A detailed discussion of this experimentation 
is given in Section 4.3.

\subsection{RESPONSE SURFACE METHODOLOGY}

Before starting the RSM analysis, the response surface was graphed. The purpose of graphing the results was to see the output response, so that a visual assessment of the response surface could be made. It was expected that this assessment could facilitate the RSM analysis. Several tools can be used to graph data, such as is Excel, Mathcad, Mathematica, SAS, and so on. Mathcad was chosen because it is capable of graphing in 3-D, and it has a very user-friendly platform.

In general, RSM is the combination of design of experiments (DOE), regression analysis, and steepest ascent/descent. The first phase (DOE) is used as a screening process. The second phase of RSM is the application of regression analysis on the data collected from the experimentation. In terms of simulation, the relationship between the input variable (factor in DOE) and the effects it has on the output response is evaluated by fitting the independent variable to a polynomial form, such as $Y=\beta_{0}+\beta_{1} X_{1}+\beta_{2} X_{2}$, where, $X_{1}$ and $X_{2}$ are the two factors and $\beta_{0}, \beta_{1}$, and $\beta_{2}$ are the unknown regression coefficients to estimate the response.

In this context, the regression process starts off by initially attempting to fit a firstdegree polynomial, i.e. it looks first for a plane to fit the surface. If the model does not pass the test of adequacy, then the process is repeated with a higher degree polynomial. A first-degree model can be written as follows: 


$$
Y=\beta_{0}+\sum_{i=1}^{k} \beta_{i} x_{i}+\varepsilon
$$

where

$$
\begin{aligned}
& Y=\text { Response Variable } \\
& \beta_{k}=\mathrm{k}^{\text {th }} \text { Regression Coefficient } \\
& \varepsilon=\text { fit error term }
\end{aligned}
$$

The test of adequacy of fitting a first-degree model is determined through the use of an $\mathrm{F}$ test. If a first-degree polynomial is not an adequate model, then it must be upgraded to a second-degree polynomial to see if this new polynomial provides a better fit for the data. A second-degree model is written as follows:

$$
Y=\beta_{0}+\beta_{1} x_{1}+\beta_{2} x_{2}+\beta_{11} x_{1}^{2}+\beta_{22} x_{2}^{2}+\beta_{12} x_{1} x_{2}+\varepsilon
$$

This process is repeated until an adequate model is found. For this effort, SPSS was used to do all regression analysis since this tool can perform linear and non-linear regression analysis.

The last phase of RSM requires to perform additional experiments along the steepest ascent plane. This plane is the one that actually looks for an optimal point on the surface. The goal of the effort was focused on understanding the behavior of the surface, not in finding a particular optimal solution. Hence. the last phase of RSM analysis was not done. 


\subsection{SUMMARY}

Various steps and techniques were used to meet the goal of this effort. The outcomes and conclusion derived from each one of them are explained in detail in Chapter 4. 


\section{CHAPTER 4:}

\section{EXPERIMENTS, ANALYSIS, AND RESULTS}

This chapter discusses the various analyses done to meet the goal. For a detail discussion of why a specific analysis was done, see Chapter 3 . The order of the discussion matches the order in Chapter 3. In other words:

- Analysis of Survey

- Simulation Model Used

- Relevant Factors and Interactions

- RSM

\subsection{ANALYSIS OF SURVEY}

A survey (Figure 2) was distributed to establish whether a generic model of an ER system could be developed. Approximately 50 hospitals were solicited and only 11 replied. All the hospitals were given exactly the same survey; yet, a few of them answered the questions in detail, while others just ignored some sections completely. Table 1 and Table 2 provide a summary of the survey responses, whereas Appendix A gives a more detailed summary of the responses. Table 1 shows that $45 \%$ of the hospitals have between two to four fast-track beds in their ER. Approximately, 27\% had no more than one bed; another, $27 \%$ had between five and eight beds, but no ER had more than 
certified. The impact of this assumption is that it will no longer be possible to model doctors as various types of resources. The same thing happened with the support technicians. In the beginning of this study, it was hoped that cost would be one of the variables (measure of performance) to observe and study; however, it was impossible to collect relevant data. Therefore, the idea was dropped.

From the processing section of the surveys, flow charts were assembled to observe the similarities and differences from one ER to another. The process flows were consolidated as in Figure 3. It was clear that there were differences in the processes followed by each ER. Some of the differences were when the registration was performed or where a critical patient goes first when arriving to the ER. Registration may be performed after the patient is triaged, or it may be performed along bedside. However, many of the processes were relatively the same.

Based on the density at each step in the ER processes, they were classified into three different classes (Figure 4 to Figure 6) of generic ER systems. Approximately, $25 \%, 12.5 \%$, and $62.5 \%$ of the ERs surveyed follow the processes of Class 1, Class 3, and Class 2 respectively. For all the classes, it should be noted that patients enter the ER by either ambulance or their own means. In the figures, the dashed lines represent the noncritical patients, whereas the solid line represents the critical patients.

Class 1 (Figure 4) represents $25 \%$ of the ERs. Patients first see a triage nurse, who has a variety of tasks, such as taking vital signs, begin a mini-registration procedure, and initiate protocols. The triage nurse assigns the acuity of the patients as soon as they enter the ER after which, if the patient is a non-critical patient, s/he goes to the waiting 
In this class (Figure 6), there are critical and non-critical patients. A Meeter Greeter at the front door first sees $25 \%$ non-critical patients before they see the triage nurse. Duties of the Meeter Greeter are to write down the name, the time the patient walked in the ER, and a chief complaint. Once this is complete, these patients join the other $75 \%$ of non-critical patients that see a triage nurse directly upon entering the ER. After triage, patients go see if there is a registration clerk available and sit in the waiting room if not. Once they have completed registering, a charge nurse (also know as communication central), is responsible for making sure a bed is available for the ER patients. The charge nurse will indicate to both the patient and doctor when the patient will be entering the treatment room. However, only some of the non-critical patients will see the charge nurse. Depending on the ER, some ERs do not have a charge nurse and consequently the patient will go directly to the treatment area. Once in the treatment area the processes are the same for all types of patients.

In Class 2, critical patients bypass the waiting room and registration, and they go directly to the treatment area or the resuscitation room (for 33.3\% of critical patients) and receive bedside (parallel) registration. In the resuscitation room, patients that are about to expire within five to fifteen minutes are stabilized and then sent over to the treatment area. After the doctor has treated the patient, the patient is transferred to the diagnostic and therapeutics area for further observation. As in the other classes, the same procedure is followed in this area. Then depending if the patient needs to be admitted into the hospital or sent home, the patient will be discharged from the ER.

The traditional simulation modeling methodology was used to build, verify, and 
validate the simulation model before the model could be used for experimentation. The simulation model was constructed using the ARENA software. A detailed flowchart of the model is given in Figure 7.

Data from a local hospital was used for the arrival process and the various service processes. These data was analyzed and appropriate probability models were established. It was noted that patient's arrival patterns follow two different distributions, depending on the time of day. Between 12:00 midnight and 6:00 A.M., patients arrive at a rate of approximately 1 patient per hour according to a Poisson distribution $(\lambda=.992)$, which implies that the interarrival time follows and exponential distribution with mean of $\approx$ 1.008 hours between patients. During the other 18 hours, patients arrive at a rate of approximately 2 per hour according to a Gamma, with mean of .599 hours between patients and a shape parameter of .478 .

In situations where the arrival rate changes, it is recommended to use the thinning process, so that entities are adequately generated. Under this approach entities are generated at the fastest rate for all periods, but the created entity is thinned out if it was not supposed to enter. The entities are thinned out probabilistically. Of the two distributions, the Gamma has the fastest rate ( 2 per hour vs. 1 per hour). Hence, it was chosen to produce the entities. However, the thinning process works well only when the distribution is the same for all periods. In this case, there are two periods and two different distributions. One distribution is Exponential, and the other is Gamma. Fortunately, the Exponential is a special case of the Gamma; hence, the Gamma can be used to represent the arrivals of both periods provided that the shape parameter is 
controlled properly. In the model, this is implemented by having variables in the entity creation mechanism. For each period the variables are given the appropriate values, so that the first period (midnight to 6:00 AM) gets an Exponential pattern, i.e. the Exponential becomes a $\operatorname{Gamma}(\lambda, 1)$, and the second period gets a $\operatorname{Gamma}(\lambda, r)$.

In the simulation model of Class $2,25 \%$ of the non-critical patients see a meeter greeter, while the rest of the non-critical patients see the triage nurse directly. The time spent at the meeter greeter was established by a mini time study. The study emulated the meeter greeter and his/her tasks. Five subjects acted as patients entering the ER with an illness. From this experimentation, a triangular distribution with parameters .5 minutes for the minimum, .85 minutes as the mode, and 1 minute as the maximum were set.

After seeing the meeter greeter, non-critical patients go to the Triage area. If there is an available triage nurse, the service begins immediately for a time that is uniform $(5,10)$. Otherwise, patients must wait until there is one available. Upon completion of the service with the triage nurse, all non-critical patients proceed to the registration area. The service at the registration area is exponentially distributed with mean of 10 minutes. After registering, non-critical patients will sit in the waiting room until a bed becomes available. The bed can be a fast-track bed, which is dedicated to non-critical patients, or a regular bed, which are for critical and non-critical patients. Regardless of what bed it is, these patients will occupy the first available bed in the ER. Then, they will start treatment. 
typically spend a certain amount of time in the ER according to their acuity level. Depending on this level the patient will remain in recovery until this amount of time minus the time spent with a doctor and nurse, whereupon patients are discharged. The times for these services follow distributions shown in Table 4. All the parameters are expressed in minutes.

In most cases, the ERs in Class 2 have parallel registration for critical patients. By the time a critical patient has been given treatment by the doctors and nurses of the ER, s/he would have been registered completely. Critical patients bypass the triage and are sent to start treatment. Thirty-three percent of critical patients will enter the Resuscitation Room. In this area, doctors and nurses perform life saving medical treatment according to the distributions for Rush Doctor Time in Table 4. Once they have been treated in this area, these patients will be transferred to the regular treatment area once there is a regular bed available and follow the same process as the other $67 \%$ of critical patients.

\begin{tabular}{|c|c|c|c|c|c|}
\hline & Doctor Time & Nurse Time & Rush Doctor Time & Max Stay \\
\hline Type 1 & Uniform $(10,2,19.8)$ & Uniform $(30,60)$ & Uniform $(5,15)$ & Erlang(1.02,4)*60 \\
\hline Type 2 & Uniform $(10.2,19.8)$ & Uniform $(30,60)$ & Uniform $(5,15)$ & Normal $(230,4,123)$ \\
\hline Type 3 & Uniform $(10,15)$ & Uniform $(30,40)$ & & Gamma $(84,1.5)$ \\
\hline Type 4 & Uniform $(1,5)$ & Uniform $(20,40)$ & & Norm $(33,12,17,7)$ \\
\hline Type 5 & Uniform $(1,5)$ & Uniform $(1,30)$ & & Norm $(33,12,17,7)$ \\
\hline
\end{tabular}

Table 4: Service Time Distributions

The complete ARENA Model is given in Appendix B. This is a non-terminating system; hence, all data is collected using a single replication. Once the model was built, 
verified and validated, the simulation length was determined using:

$$
\mathrm{SL}=\mathrm{T}+\mathrm{WT}+\mathrm{ST}
$$

$$
\begin{aligned}
& \text { where } \quad \begin{array}{l}
\mathrm{SL}=\text { Simulation Length } \\
\mathrm{T}=\text { time to generate observations, } \\
\mathrm{WT}=\text { warm up time, and } \\
\mathrm{ST}=\text { safety time for this system. }
\end{array}
\end{aligned}
$$

At least 15 batches were needed in order to obtain unbiased results; thus, the values used were:

$$
\mathrm{SL}=27,272+2,000+738=32,000
$$

Now the model was ready to serve as an experimental tool.

\subsection{DETERMINING RELEVANT INTERACTIONS}

In addition to the simulation model, the survey assisted in establishing different factors and their levels. These are registration clerk, triage nurse, registered nurses $(3,13)$, doctors $(1,4)$, regular beds $(10,28)$, and fast track beds $(1,4)$. Since there was no data on the number of registration clerks and triage nurses available, it was assumed that these factors would be kept at the constant level of one. These factors and levels yield 3,344 experiments. However, since it would be time consuming to test all combinations, a fractional factorial experiment was developed. Only 25 treatments were explored considering the length of each replication, and the time it would take to generate output from each experiment and analyze them. Table 5 gives the 25 experiments generated 
increased. This expected behavior is observed for patients type 4 (Figure 9) and type 5 (Figure 10); yet, the reverse occurs for patients type 2 (Figure 11). A similar behavior is observed for type 2 when the factor varied is doctors (Figure 12) and for most types when the factor varied is regular bed (Figure 13 to Figure 16). How can this be? Table 6 was created to help understand the reason for the upward slope of time in the system vs. increase number of resources (nurses). However, this attempt was unsuccessful. Several suggestions to better understand this situation are to experiment with the model by creating equal proportions for all patient types. This experimentation may clarify if the behavior is due to patient type interaction. Another suggestion is to just create one patient type for the whole experiment to see the relationship between the number of resources and the time in the system, one patient type at a time.

An idea about why these patients have such erratic behavior may be due to the fact that once they enter the ER and have attained a bed, they must wait until a nurse is available. Patient type 1 enters the resuscitation room and gets stabilized, yet, once they get stabilized they must wait for as long as needed until the first bed is available. Patients type 3, 4, and 5 enter the ER as soon as a bed is available and continue to wait there until a nurse is ready for them. Another suggestion is to run more experiments from the 3,344 available, which may demonstrate a clearer trend in the data. 
by testing the equality of the means. In other words, by testing

$$
\begin{aligned}
& H_{0}: \mu_{i}=\mu_{j} \quad \forall i, j \\
& H_{1}: \mu_{i} \neq \mu_{j} \quad \text { for at least one } \mathrm{i} \neq \mathrm{j} .
\end{aligned}
$$

The null hypothesis $\mathrm{H}_{0}$ is rejected with significance level of $\alpha$ if

$$
\begin{aligned}
& \qquad \mathbf{F}_{0}>\mathbf{F}_{\alpha ; \nu 1 ; v 2} \\
& \text { where } \quad \mathbf{F}_{0}=\frac{\text { variation among group means }}{\text { variation within groups }} \\
& \mathbf{F}_{\alpha ; v 1 ; v 2}=\text { critical value } \\
& v 1=\text { degrees of freedom between groups } \\
& v 2=\text { degrees of freedom within groups }
\end{aligned}
$$

For this analysis, the two factors under consideration are the number of nurses and number of doctors. The significance level chosen was $\alpha=0.05$ and with $v 1=2$ and $v 2=$ 22. Table 9 shows a summary of the various significance values for the individual factors and interactions for all types, whereas Appendix D provides detailed ANOVA tables. Nurses shows that it is most significant when dealing with patients type 4 and 5. For patients type 2 , technically speaking it shows that it is not significant; however, it did not meet the requirement by a very small margin. When checking the significance of doctors, the table shows that it is not significant for type 5. Regardless of these individual assessments, the interaction of both factors is statistically significant. 


\begin{tabular}{|c|}
\hline SELECT CASE ND: \\
CASE ND $=1$ \\
IF NN $\geq 6$ THEN \\
Increase NN by 0 \\
ELSE \\
Increase NN by 1 \\
END IF \\
CASE ND $=2:$ \\
IF $6 \leq$ NN $\leq 8$ THEN \\
Increase NN by 2 \\
ELSE \\
Increase NN by 0 \\
END IF \\
END SELECT ND \\
Nhere $=$ number of nurses in the ER \\
ND $=$ number of doctors in the ER \\
\hline
\end{tabular}

Table 12: Rules to change Nurses for Tsys2

\begin{tabular}{|c|}
\hline SELECT CASE NN \\
CASE NN $\geq 6$ \\
SELECT CASE ND \\
CASE ND $=1$ \\
Increase ND by 3 \\
CASE ND $=2$ \\
Increase ND by 2 \\
CASE ND $=3$ \\
Increase ND by 1 \\
CASE ND $=4$ \\
Increase ND by 0 \\
CASE ND $\geq 5$ THEN \\
Increase ND by -1 \\
END SELECT ND \\
END SELECT NN
\end{tabular}

Table 13: Rules to change Doctors for Tsys2

A more extensive experimentation needs to be done to improve these rules so that the utilization of the resources is also taken into account. Also, other rules could be 
derived. These rules could be used in several ways in the context of simulation studies. An example is to use these rules to guide an expert system that changes parameter in the context of goal driven simulation.

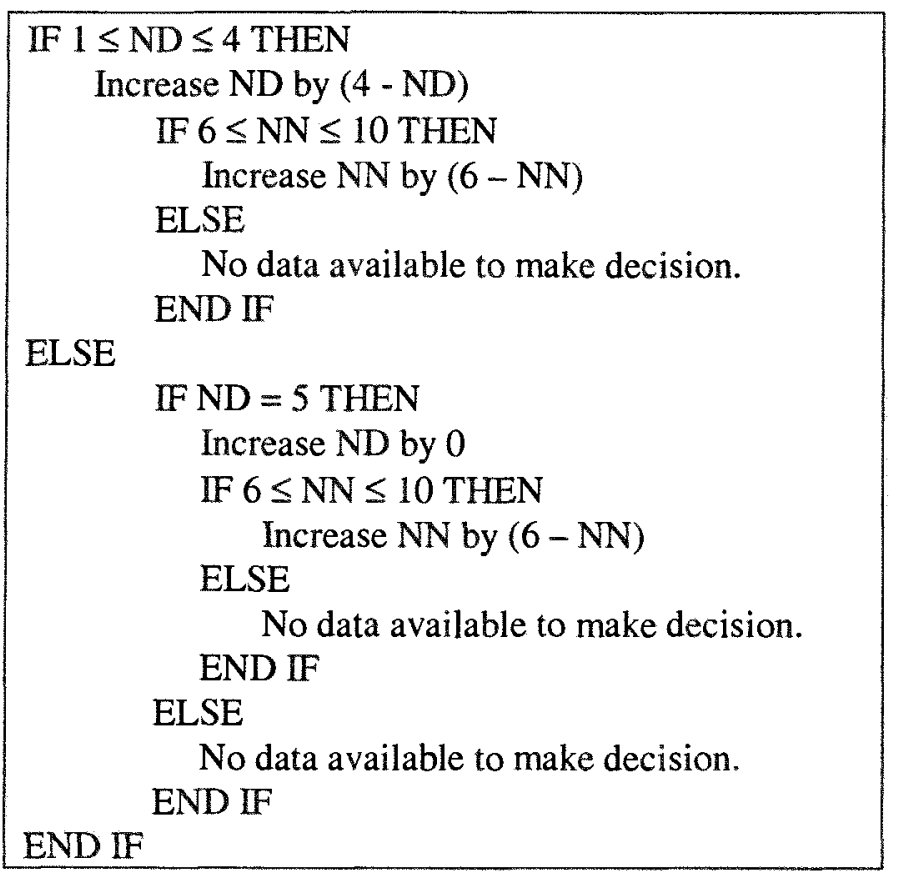

Table 14: Combined Production Rules for Tsys2

Figure 19 shows the behavior of Tsys4. It shows that when there are less than 3 doctors present, increasing the resource doctor by one unit will drastically reduce time in the system for patients type 4 . Once there are 3 or more doctors, the time in the system levels off, i.e. adding units of the resource doctors has no impact on Tsys4. Some of the decision rules that may be derived for Tsys 4 in Table 15 and Table 16. As in Tsys2, the production rules of greater interest are when the number of nurses and the number of doctors would change simultaneously. Table 17 shows the simultaneous changes for 


\begin{tabular}{|c|}
\hline SELECT CASE NN \\
CASE NN $\geq 6$ \\
SELECT CASE ND \\
CASE ND $=1$ \\
Increase ND by 3 \\
CASE ND $=2$ \\
Increase ND by 2 \\
CASE ND $=3$ \\
Increase ND by 1 \\
CASE ND $=4$ \\
Increase ND by 0 \\
CASE ND $\geq 5$ THEN \\
Increase ND by -1 \\
END SELECT ND \\
END SELECT NN
\end{tabular}

Table 16: Rules to change Doctors for Tsys4

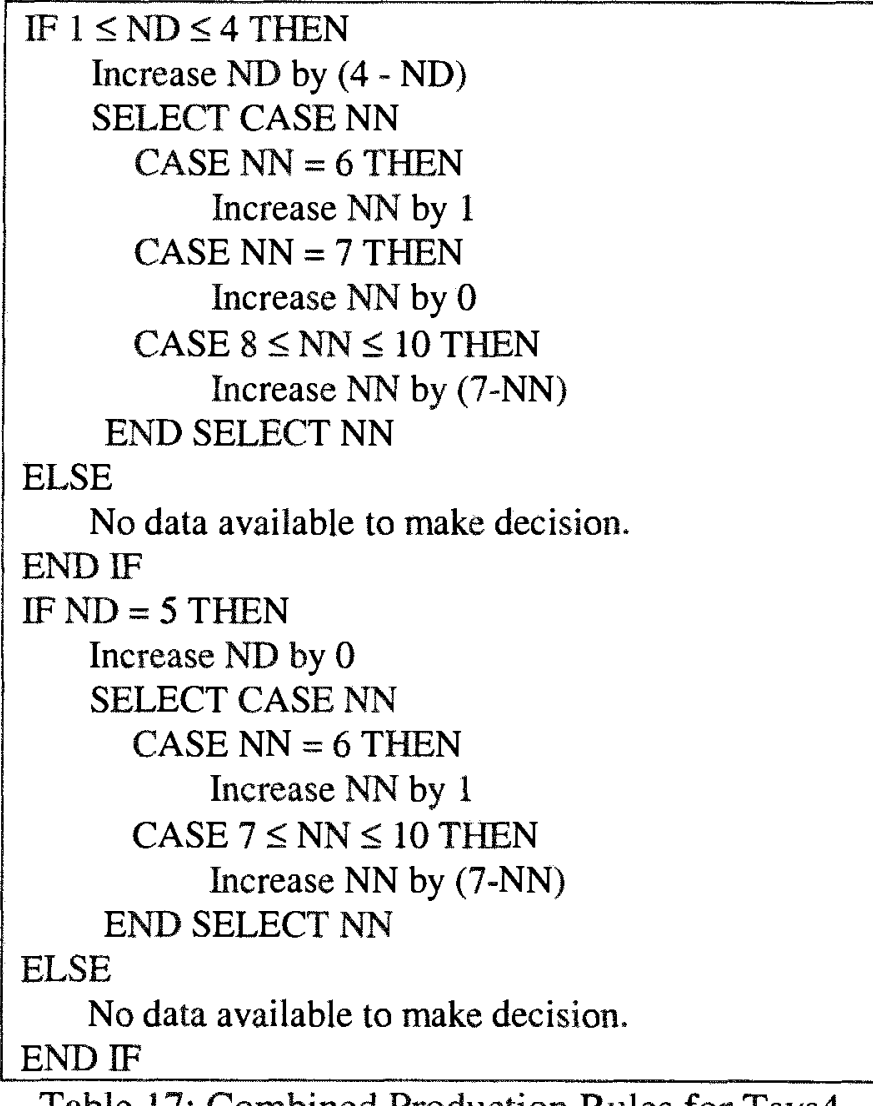

Table 17: Combined Production Rules for Tsys4 
Table 18 shows the results of fitting the following polynomial for Tsys4. These results yield the following first-degree models:

$$
\hat{Y}_{T s y s 4}=72.812-.18 x_{1}-1.39 x_{2}
$$

where $x_{1}=$ nurses and $x_{2}=$ doctors. The true values for $\beta_{0}, \beta_{1}$, and $\beta_{2}$ lie somewhere, with 95\% confidence, between the intervals of (Figure 20):

$$
\begin{aligned}
& 68.36 \leq \beta_{0} \leq 77.27, \\
& -0.70 \leq \beta_{1} \leq 0.33, \text { and } \\
& -1.90 \leq \beta_{2} \leq-0.87 .
\end{aligned}
$$

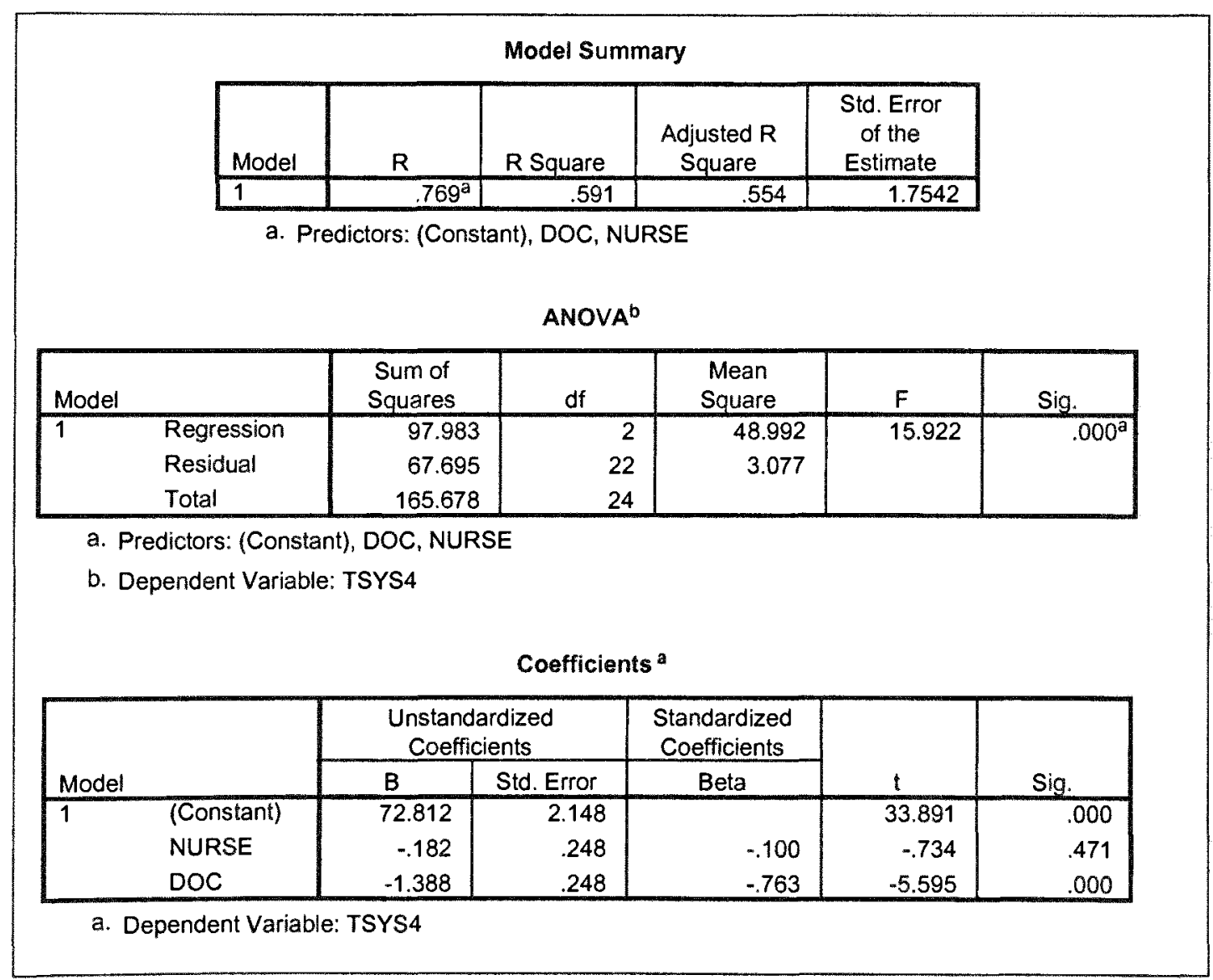

Table 18: First-Degree Fitted Model for Tsys4 
Nonetheless, several decision rules may be formulated as shown in Table 20 and Table 21.

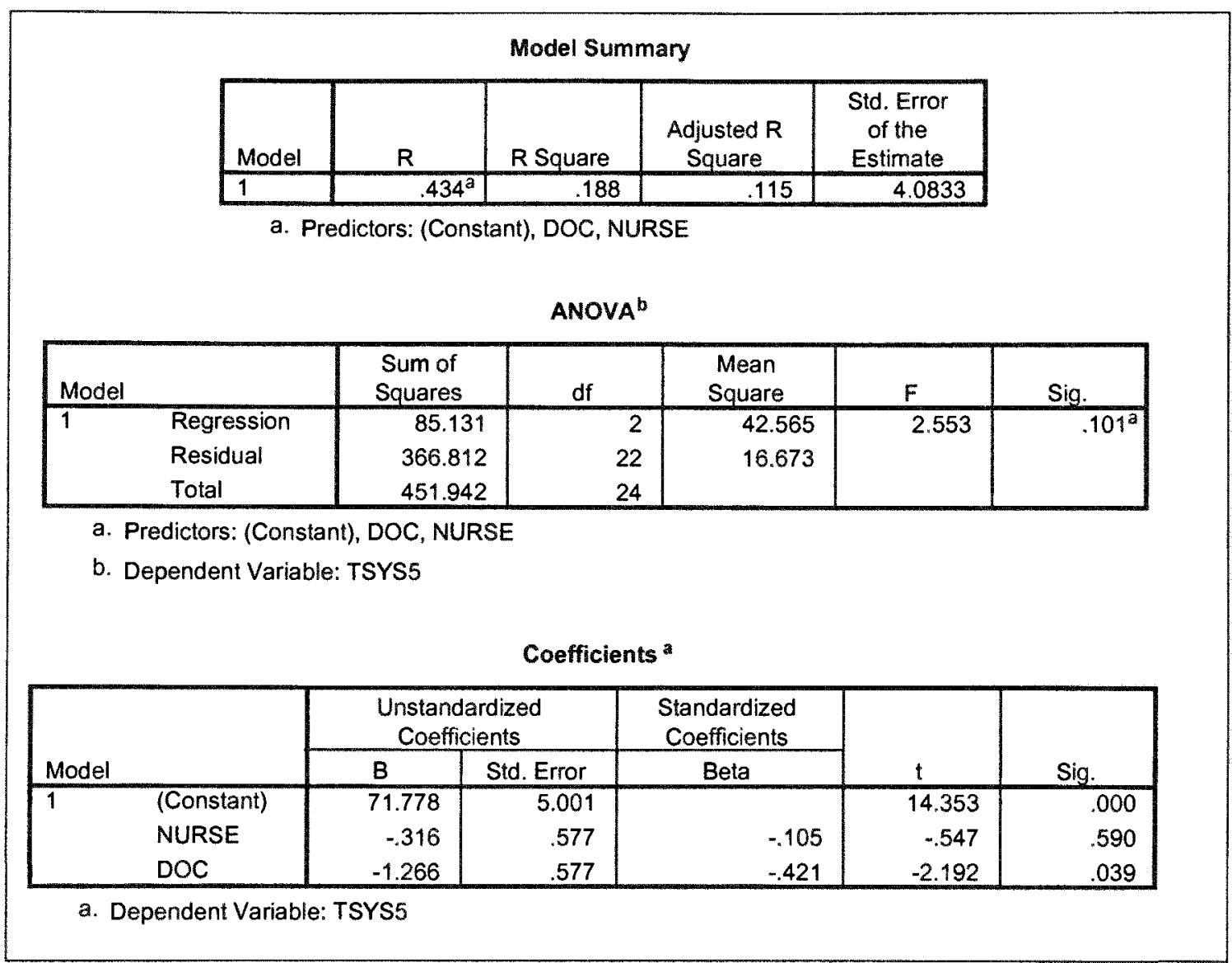

Table 19: First-Degree Fitted Model for Tsys5 


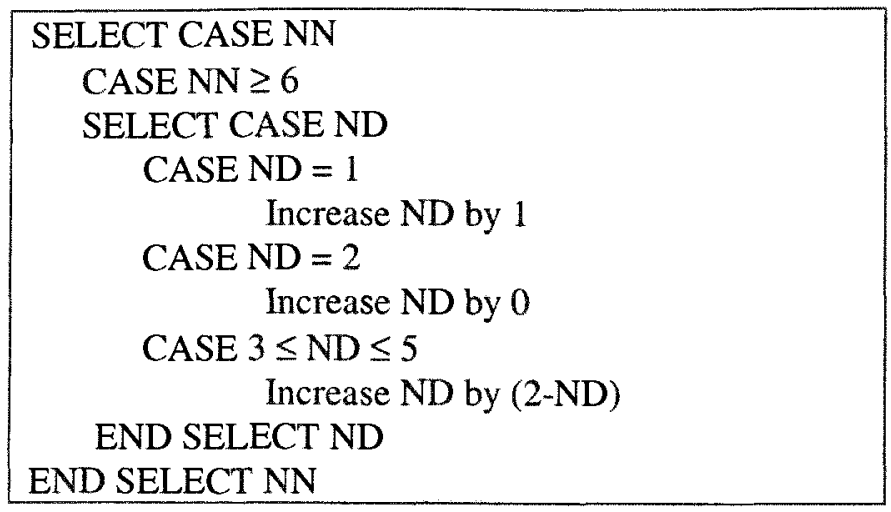

Table 21: Rules to Change Doctors for Tsys5

Understanding the behavior of the three surfaces simultaneously was a new challenge altogether. The first thing that was observed was that the range for Tsys was very different for each type of patient. Thus, Tsys 4 and Tsys 5 had to be scaled, so that the three surfaces could be graphed simultaneously. The scale adjustment used was:

$$
\frac{\left(T s y s_{i j}-L V F\right)}{R F} * R F^{*}+L V F^{*}
$$

where

$$
\begin{aligned}
& i=\text { patient type ( } 4 \text { or } 5 \text { ) } \\
& j=\text { experiment number ( } 1 \text { to } 25 \text { ) } \\
& \text { Tsys }_{i j}=\text { Time in the system for patient type } i \text { from experiment } j \\
& L V F=\text { Lowest Value of Factor being scaled } \\
& R F=\text { Range of Tsys } i j \\
& L V F^{*}=\text { Lowest Value of Factor being scaled up to } \\
& R F^{*}=\text { Range Tsys being scaled up to }
\end{aligned}
$$

Thus, the equation for Tsys 4 is: 


$$
\frac{\left(T_{s y s_{4 j}}-65\right)}{8} * 43+222
$$

and the equation for Tsys 5 is:

$$
\frac{\left(T s y s_{5_{j}}-60\right)}{18} * 43+222
$$

Which yielded the values shown in Table 22 .

\begin{tabular}{|c|c|c|c|}
\hline Experiments & $\begin{array}{c}\text { Non-scaled } \\
\text { Tsys2 }\end{array}$ & $\begin{array}{c}\text { scaled } \\
\text { Tsys4 }\end{array}$ & $\begin{array}{c}\text { scaled } \\
\text { Tsys5 }\end{array}$ \\
\hline 1 & 235 & 267 & 251 \\
\hline 2 & 254 & 259 & 266 \\
\hline 3 & 242 & 260 & 250 \\
\hline 4 & 265 & 259 & 249 \\
\hline 5 & 265 & 259 & 249 \\
\hline 6 & 253 & 242 & 222 \\
\hline 7 & 239 & 227 & 223 \\
\hline 8 & 227 & 228 & 222 \\
\hline 9 & 227 & 228 & 224 \\
\hline 10 & 227 & 227 & 224 \\
\hline 11 & 234 & 227 & 235 \\
\hline 12 & 262 & 226 & 233 \\
\hline 13 & 260 & 226 & 233 \\
\hline 14 & 258 & 226 & 233 \\
\hline 15 & 258 & 226 & 233 \\
\hline 16 & 222 & 226 & 235 \\
\hline 17 & 260 & 225 & 233 \\
\hline 18 & 255 & 226 & 233 \\
\hline 19 & 253 & 226 & 232 \\
\hline 20 & 253 & 226 & 232 \\
\hline 21 & 222 & 226 & 235 \\
\hline 22 & 260 & 225 & 233 \\
\hline 23 & 255 & 226 & 233 \\
\hline 24 & 253 & 226 & 232 \\
\hline 25 & 253 & 226 & 232 \\
\hline & 226 & \\
\hline
\end{tabular}

Table 22: Scaled Factors

Once the factors for Tsys 4 and Tsys 5 were scaled, they were combined into one graph as in, Figure 23. This graph shows the behavior of the system from the doctor's 
axis. It seems that when the system has less than 2 doctors, the behavior is quite similar for all three types. When there is only 1 doctor, all the times in the systems are at their highest. As soon as there are 2 doctors, however, the time drastically reduces. Moreover, the graph demonstrates that as 3 doctors or more are present patients type 4 and 5 maintain a low level of time in the system, leading to the conclusion that the patients that benefit the most of increasing doctors are those less critical. Once again, the behavior of Type 2 patients is awkward since they tend to spend more time in the system. This behavior requires further investigation. It is worth noting that the time in the system for all three patient types levels out after Doctors reaches 4 clearly indicating that the threshold for efficiently adding units of this resource is relatively low. It would be interesting to study how sensitive is this threshold to the demand of the ER.

From Figure 24 and Figure 25, it is possible to see that the resource Nurses has a minimal impact on the time in the system. This may be due to the fact that the level of this resource began at 6 , not at 1 . 


\section{CHAPTER 5:}

\section{CONCLUSIONS AND FUTURE WORK}

By gaining an understanding of the input and output relationships in ER systems, it has been possible to derive decision rules that may help in the development of algorithms and heuristics to optimize simulation output. This effort has shed significant light on the behavior of the ER systems. Based on the data collected and the analysis done (as described in Chapter 3 and 4), several conclusions have been drawn and several lessons learned. Among these are the following:

- It is possible to have a generic model. Specifically, three different classes were derived, with Class 1 and Class 3 having significant overlap with Class 2.

- Of the four independent variables that were considered, Nurses and Doctors were found to be the most significant for most patient types.

- The interaction among the factors, mainly doctors and nurses, were found to have a high significance level.

- When applying RSM to the data it was concluded that linear regression was not useful in explaining the variation of the dependent variable, Tsys. Hence, only rules can be formulated at this point.

- Production rules were derived for the purpose of modifying model inputs. These production rules may be useful for the purpose of goal driven 
simulation. Improvements to these production rules would be beneficial if the utilization of the resources were taken into account.

Despite these significant contributions, this effort should be further continued to make these conclusions stronger, and to further understand these ER systems. Some suggestions for further extension of this work include:

- Explore more treatments: There are a total of 3,344 experiments that are needed to fully see the effects on the response surface. This effort only explored 25 of them. It would be relatively simple to repeat the analysis in Section 4.3 for the other set of 25 treatments. The purpose for these experiments would be to see if having more data added to the information provided in this effort will show any trends in the behavior.

- Remove outliers: Re-evaluate the data of the original 25 experiments and remove any outlier that there might be. This will help understand and explain why the slope of some of these relationships is positive. As part of this reevaluation, other non-linear regression model may be considered. As a result of removing these outliers, the standard deviation may drastically reduce; hence, the analysis of this section may change. However, careful investigation of these observations is in order, because it may be that these observations provide special circumstances to the study.

- Explore other measures of performance: The DOE analysis revealed a curious behavior for Tsys for patient type 1. Since these are the most ill patients, maybe what should be studied is the time in the queue (Tque) after 
they have been stabilized. In fact, it may be altogether more revealing to look at the Tque rather than Tsys because it offers a natural convergence point: zero. Not only should Tque be analyzed, but the utilization of resources must be looked into. Having more resources available may not be the answer. There may be a small number of beds available and yet have many nurses waiting around to provide care for patients.

- Re-evaluate this effort with fixed demand of patients: Creating an equal number of patient per type may reveal a clearer relationship between the type of patient and the resources. This may explain the output behavior of time in the system for a particular type of patient. 


\section{REFERENCES}

Alvarez, A. M., 1999. “A Simulation-Based Decision Support System For Evaluating Operating Policies in an Emergency Room Facility" Master's Thesis, Florida International University, 1999.

Amaral, J. N., K. Tumer, and J. Ghosh, 1992. "Applying Genetic Algorithms to the State Assignment Problem: A Case Study." Adaptive and Learning Systems, 2-13.

Anderson, V. L. and R. A. McLean, 1974. Design of Experiments: A Realistic Approach, New York, NY: Marcel Dekker, Inc.

Azadivar, F., 1992. "A Tutorial on Simulation Optimization." Proceedings of the 1992 Winter Simulation Conference, J. J. Swain, D. Goldman, R. C. Crain, and J. R. Wilson (eds.), 198-204.

Baptist Health Systems,1998. "About Us." Baptist Health Systems of South Florida. URL: http://www.baptisthealth.net/about/statistics.html, (7 Dec. 1998).

Benson, D., 1997. "Simulation Modeling and Optimization Using Promodel." Proceedings of the 1997 Winter Simulation Conference, S. Andradóttir, K. J. Healy, D. H. Withers, and B. L. Nelson (eds.), 587-593.

Boning, D. S. and P. K. Mozumder, 1994. "DOE/Opt: A System for Design of Experiments, Response Surface Modeling, and Optimization Using Process and Device Simulation." IEEE Transactions on Semiconductor Manufacturing, 7(2), 233246. 
Carson, Y. and A. Maria, 1997. "Simulation Optimization: Methods and Applications." Proceedings of the 1997 Winter Simulation Conference, S. Andradóttir, K. J. Healy, D. H. Withers, and B. L. Nelson (eds.), 118-126.

Chen, H. and B. W. Schmeiser, 1994. "Retrospective Approximation Algorithms for Stochastic Root Finding." Proceedings of the 1994 Winter Simulation Conference, J. D. Tew, S. Manivannan, D. A. Sadowski, and A. F. Seila (eds.), 255-261.

Chiu, C. C., J. J. Pignatiello, and D. F. Cook, 1994. "Response Surface Methodology for Optimal Neural Network Selection." Proceedings of the International Conference on Tools with Artificial Intelligence, IEEE, Piscataway, NJ, 161-167.

ENA, 1997. ENA-National Emergency Department Database Survey Summary. Emergency Nurses Association (ENA); Parkridge, IL: ENA

Evans, G. W., B. Stuckman, and M. Mollaghasemi, 1991. "Multicriteria Optimization of Simulation Models." Proceedings of the 1991 Winter Simulation Conference, B. L. Nelson, W. D. Kelton, G. M. Clark (eds.), 894-900.

Evans, G. W. and M. Mollaghasemi, 1994. "Multicriteria Design of Manufacturing Systems Through Simulation Optimization." IEEE Transactions on Systems, Man and Cybernetics, 24(9), 1407-1411.

Freedman, R.W., 1994. "Reduction of the Average Length of Stay in the Emergency Room Using Discrete Simulation." Proceedings of the Simulation in Health Sciences Conference, Anderson and Katzper (eds.), 6-8. 
Fu, M. C., 1994a. "A Tutorial Review of techniques for Simulation Optimization." Proceedings of the 1994 Winter Simulation Conference, J. D. Tew, S. Manivannan, D. A. Sadowski, and A. F. Seila (eds.), 149-156.

Fu, M. C., 1994b. "Optimization Via Simulation: A Review." Annals of Operations Research, 53, 199-247.

Fu, M. C. and K. J. Healy, 1997. "Techniques for Optimization Via Simulation: An Experimental Study on an (s, S) Inventory System." IIE Transactions, 29 (3), 191199.

Garcia, M. L., M. A. Centeno, C. Rivera, and N. DeCario, 1995. "Reducing Time in an Emergency Room Via a Fast-Track." Proceedings of the 1995 Winter Simulation Conference, C. Alexopoulos, K. Kang, W. R. Lilegdon, and D. Goldsman (eds.), 1048-1053.

Gaston, G. J. and A. J. Walton, 1994. "Intergration of Simulation and Response Surface Methodology for the Optimization of IC Processes." IEEE Transactions on Semiconductor Manufacturing, 7(1), 22-33.

Healy, K. and L. W. Schruben, 1991. "Retrospective Simulation Response Optimization." Proceedings of the 1991 Winter Simulation Conference, B. L. Nelson, W. D. Kelton, G. M. Clark (eds.), 901-906.

Healy, K. J., 1994. "Identifying Policies That Are Most Likely to Produce a Desirable Outcome." Proceedings of the 1994 Winter Simulation Conference, J. D. Tew, S. Manivannan, D. A. Sadowski, and A. F. Seila (eds.), 387-391. 
Hood, S. J. and P. D. Welch, 1993. "Response Surface Methodology and its Application in Simulation." Proceedings of the 1993 Winter Simulation Conference, G. W. Evans, M. Mollaghasemi, E. C. Russell, W. E. Biles (eds.), 115-122.

Hsu, J. C. and B. L. Nelson, 1988. "Optimization over a Finite Number of System Design with One-Stage Sampling and Multiple Comparison With the Best." Proceedings of the 1990 Winter Simulation Conference, M. Abrams, P. Haigh, and J. Comfort (eds.), $451-457$.

Kirtland, A., J. Lockwood, K. Poisker, L. Stamp, and P. Wolfe, 1995. "Simulating an Emergency Department 'Is As Much Fun As...'” Proceedings of the 1995 Winter Simulation Conference, C. Alexopoulos, K. Kang, W. R. Lilegdon, and D. Goldsman (eds.), 1039-1041.

Kleijnen, J. P. C., 1995. "Sensitivity Analysis and Optimization in Simulation: Design of Experiments and Case Studies." Proceedings of the 1995 Winter Simulation Conference, C. Alexopoulos, K. Kang, W. R. Lilegdon, and D. Goldsman (eds.), 133140.

Korngold, J. C. and G. A. Gabriele, 1997. "Multidisciplinary Analysis and Optimization of Discrete Problems Using Response Surface Methods." Journal of Mechanical Design, Transactions of the ASME, 119 (4), 427-433.

Lee, Y., H. Shin, and B. Yang, 1996. "An Approach for Multiple Criteria Simulation Optimization with Application to Turning Operation." Computers \& Industrial Engineering, 30 (3), 375-386. 
Lowder, B., 1997. "Durham Regional Saves $\$ 150,000$ Annually Using Simulation Tools." Simulation Success, 1997.

Lowery, J. C., 1996. "Introduction to Simulation in Health Care." Proceedings of the 1996 Winter Simulation Conference, J. M. Charnes, D. J. Morrice, D. T. Brunner, and J. J. Swain (eds.), 78-84.

Manansang H. and J. A. Heim, 1996. "An On-Line, Simulation-Based Patient Scheduling System." Proceedings of the 1996 Winter Simulation Conference, J. M. Charnes, D. J. Morrice, D. T. Brunner, and J. J. Swain (eds.), 1170-1175.

McGuire, F., 1994. "Using Simulation to Reduce Length of Stay in Emergency Departments." Proceedings of the 1994 Winter Simulation Conference, J. D. Tew, S. Manivannan, D. A. Sadowski, and A. F. Seila (eds.), 861-867.

Pallin, A. and R. P. Kittell, 1992. "Mercy Hospital: Simulation Techniques for ER Processes." Industrial Engineering, 24(2), 35-37.

Pegden, C. D., R. E. Shannon, and R. P. Sadowski, 1995. Introduction to Simulation Using SIMAN, New York, NY: McGraw-Hill, Inc.

Rardin, R. L., 1998. Optimization in Operations Research, Upper Saddle River, NJ: Prentice-Hall, Inc.

Safizadeh, M. H., 1990. "Optimization in Simulation. Current Issues and the Future Outlook." Naval Research Logistics, 37(6), 807-825.

Shaffer, R. E., 1999. "Simulated Annealing." CHEMOmetrics on the WEB. Last revision 4/26/99. URL: http://chem1.nrl.navy.mil/ shaffer/chemoweb.html (3 March 1999).

Talukdar, S. N., 1998. ECE People. URL: 
http://www.ece.cmu.edu/people/fac/talukdar.html, (18 March 1999).

Tompkins, G. and F. Azadivar, 1995. "Genetic Algorithms in Optimizing Simulated Systems." Proceedings of the 1995 Winter Simulation Conference, C. Alexopoulos, K. Kang, W. R. Lilegdon, and D. Goldsman (eds.), 757-762.

Yunker, J. M. and J. D. Tew, 1994. "Simulation Optimization by Genetic Search." Mathematics and Computers in Simulation, 37 (1), 17-28. 


\section{OTHER RELEVANT LITERATURE USED}

Andradóttir, S., 1992. "Discrete Optimization in Simulation: A Method and Applications." Proceedings of the 1992 Winter Simulation Conference, J. J. Swain, D.

Goldsman, R. C. Crain, and J. R. Wilson (eds.), 483-486.

Box, G. E. P. and N. R. Draper, 1987. Empirical Model-Building and Response Surfaces, New York, NY: John Wiley \& Sons, Inc.

Clark, G. M., 1990. "Use of Common Random Numbers in Comparing Alternatives." Proceedings of the 1990 Winter Simulation Conference, O. Balci, R. P. Sadowski, R. E. Nance (eds.), 367-371.

Cook, L. S., 1993. "A Methodology for Factor Screening for Multiple Response Computer Simulation Models." Proceedings of the 1993 Winter Simulation Conference, G. W. Evans, M. Mollaghasemi, E. C. Russell, W. E. Biles (eds.), 13761377.

Cornell, J. A., 1990. "Volume 8: How to Apply Response Surface Methodology." American Society for Quality Control, S. S. Shapiro and E. F. Mykytka (eds), 1990.

Del Vecchio, R. J., 1997. Understanding Design of Experiments, Cinninnati, Ohio: Hanser/Gardner Publications, Inc.

Draper, N. R. and H. Smith, 1966. Applied Regression Analysis, New York, NY: John Wiley \& Sons, Inc. 
Goldsman, D. and B. L. Nelson, 1990. "Batch-Size Effects on Simulation Optimization

Using Multiple Comparison with the Best." Proceedings of the 1990 Winter Simulation Conference, O. Balci, R. P. Sadowski, R. E. Nance (eds.), 288-293.

Goldsman, D. and B. L. Nelson, 1991. "Methods for Selecting the Best System." Proceedings of the 1991 Winter Simulation Conference, B. L. Nelson, W. D. Kelton, G. M. Clark (eds.), 177-186.

Goldsman, D. and B. L. Nelson, 1994. "Ranking and Selection and Multiple Comparison in Computer Simulation." Proceedings of the 1994 Winter Simulation Conference, J. D. Tew, S. Manivannan, D. A. Sadowski, and A. F. Seila (eds.), 192-199.

Goodhart, S. G., K. J. Burnham, and J. G. James, 1991. “A Retrospective Self-Tuning Controller." International Journal of Adaptive Control and Signal Processing, 5(4), 283-292.

Grabau, M. R. and R. A. Maurer, 1997. "Using a Simulation to Generate the Data to Balance an Assembly Line." Proceedings of the 1997 Winter Simulation Conference, S. Andradóttir, K. J. Healy, D. H. Withers, and B. L. Nelson (eds.), 733-738.

Harrison, P. N., R. Le Riche, and R. T. Haftka, 1995. "Design of Stiffened Composite Panels by Genetic Algorithm and Response Surface Approximations." Proceedings of the $36^{\text {th }}$ AIAA/ASME/ASCE/AHS/ASC Structures, Structural Dynamics, and Materials Conference, 1, 58-68.

Hoffman, L. L., 1991. "Choosing the Best Set of Quality Judges: A New Quality Tool.” Quality and Reliability Engineering International, 7, 475-478. 
Joshi, B., D. Morris, N. White, and R. Unal, 1996. "Optimization of Operations Resources via Discrete Event Simulation Modeling." $6^{\text {th }}$ Symposium on Multidisciplinary Analysis and Optimization, Bellevue, WA.

Khuri, A. I. and J. A. Cornell, 1987. Response Surfaces Designs and Analyses, New York, NY: Marcel Dekker, Inc.

Kolonja, B., D. R. Kalasky, and J. M. Mutmansky, 1993. "Optimization of Dispatching Criteria for Open-Pit Truck Haulage System Design Using Multiple Comparisons with the Best and Common Random Numbers." Proceedings of the 1993 Winter Simulation Conference, G. W. Evans, M. Mollaghasemi, E. C. Russell, W. E. Biles (eds.), 393-400.

Kuehl, R. O., 1994. Statistical Principles of Research Design and Analysis, Belmont, CA: Wadsworth, Inc.

Matejcik, F. J. and B. L. Nelson, 1993. "Simultaneous Ranking, Selection and Multiple Comparisons for Simulation." Proceedings of the 1993 Winter Simulation Conference, G. W. Evans, M. Mollaghasemi, E. C. Russell, W. E. Biles (eds.), 386391.

Meketon, M., 1987. "Optimization in Simulation: A Survey of Recent Results." Proceedings of the 1987 Winter Simulation Conference, A. Thesen, H. Grant, W. David Kelton (eds.), 58-67.

Mollaghasemi, M. and G. W. Evans, 1994. "Multicriteria Design of Manufacturing Systems through Simulation Optimization." IEEE Transactions on Systems, Man and Cybernetics, 24 (9), 1407-1411. 
Nakayama, M. K., 1995. "Selecting the Best System in Steady-State Simulations Using Batch Means." Proceedings of the 1995 Winter Simulation Conference, C. Alexopoulos, K. Kang, W. R. Lilegdon, and D. Goldsman (eds.), 362-366.

Reyes, M. F., 1998. "A Heuristic for On-Line Assessment of Simulation Output for Goal Driven Simulation." Master's Thesis, Florida International University, 1998.

Robinson, S. M., 1996. "Analysis of Sample-Path Optimization." Mathematics of Operations Research, 21(3), 513-528.

Schulz, J. B., 1995. "MedModel-Healthcare Specific Simulation Software." Proceedings of the 1995 Winter Simulation Conference, C. Alexopoulos, K. Kang, W. R. Lilegdon, and D. Goldsman (eds.), 476-481.

Shi, L. and S. Olafsson, 1997. "An Integrated Framework for Deterministic and Stocastic Optimization." Proceedings of the 1997 Winter Simulation Conference, S. Andradóttir, K. J. Healy, D. H. Withers, and B. L. Nelson (eds.), 358-365.

Smith, G., 1998. Introduction to Statistical Reasoning, New York, NY: The McGrawHill Companies, Inc.

Tempelmeier, H. and H. Kuhn, 1993. Flexible Manufacturing Systems: Decision Support for Design and Operation, New York, NY: John Wiley \& Sons, Inc.

Wallace, R. J. and E. C. Freuder, 1993. "Conjunctive Width Heuristics for Maximal Constraints Satisfaction." Proceedings of the National Conference on Artificial Intelligence, 762-768. 
Wang, X. A. and R. L. Mahajan, 1995. "CVD Epitaxial Deposition in a Vertical Barrel Reactor: Process Modeling and Optimization Using Neural Network Models." Journal of the Electrochemical Society, 142(9), 3123-3132.

Wu, K. Y., Y. Shen, R. M. M. Chen, and A. Wu, 1996. "A Parallel Optimal Statistical Design Method Based in Genetic Algorithm." Proceedings of the 1996 IEEE International Symposium on Circuits and Systems, 477-480.

Yang, W. and B. L. Nelson, 1991. "Using Common Random Numbers and Control Variates in Multiple-Comparison Procedures." Operations Research, 39(4), 583-591. 


\section{APPENDICES}




\section{APPENDIX A}

The first table is the raw data from the collection of surveys. It was used to come up with the boundaries of the levels for the factors nurses, doctors, and the two types of beds, fast track and regular beds. The second table shows the percentage of how each question was answered for the five questions discussed in Section 4.1. 


\section{APPENDIX B}

This appendix shows the Model frame and the Experimental frame of the simulation model developed for the generic model. 


\section{Model Frame}

$0 \$$

vble, 1)*7:MARK (Time_ER);

CREATE,

1,0.001:Gamma (1/MaxRate, $87 \$$

BRANCH，

$1,10:$

With, ArrivalRate (period) /MaxRate, 36\$, Yes:

Else, 88\$, Yes;

36\$ COUNT: enter_patients, 1 ;

$1 \$$

ptype $=$ discrete $(.08177,1, .11112,2, .51782,3, .96646,4,1,5,4)$ :

ASSIGN :

$\operatorname{DrT}=E D$ (ptype) :

Nurse $=E D($ ptype +5$)$ :

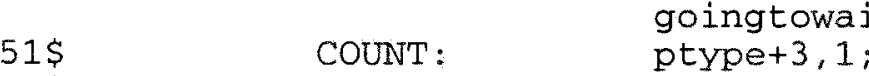

65\$ BRANCH, 1,10:

If, ptype $==1$. or.ptype $==2$, CheckBedAvail, Yes :

CheckBedAvail BRANCH, 1,10 :

If , NR (RGBed) $==$ MR (RGBed) . and. NR (RushBed) $==$ MR (RushBed), OutER, Yes :

$\begin{array}{lll}\text { OutER } & \text { COUNT: } & \text { Else, } 2 \$, \text { Yes; } \\ 3 \$ & \text { DISPOSE; } & \text { AnotherHospital, } 1 ;\end{array}$

$2 \$ \quad$ BRANCH, $1,10:$

With, $.33,76 \$$, Yes:

Else, 101\$, Yes;

$76 \$$ COUNT: ptype+8,1;

$74 \$ \quad$ ASSIGN: $\quad$ DrRushT $=E D($ ptype+10);

$75 \$$ ROUTE: 0.0 , RushForBed;

101\$ BRANCH, 1,10:

If, NR (RGBed) $==$ MR (RGBed), OutER, Yes :

$\begin{array}{lll}77 \$ & \text { COUNT: } & \text { Else, } 77 \$, \text { Yes; } \\ 38 \$ & \text { ROUTE: } & 0.0,1 ; \text { RegularBeds; } \\ 92 \$ & \text { BRANCH, } & 1,10:\end{array}$

If , nq(1) +nq(2)+nq(3)+nq(9)+nr(1)+nr(2)+nr(7) .gt. 30, noroom, Yes:

noroom COUNT: Noentry, 1 ;

91\$ DISPOSE;

go_get_branch BRANCH, 1,10 :

With, $25,80 \$$, Yes:

Else, 79\$, Yes:

$80 \$$ COUNT: willgreet, 1 ;

$68 \$$ ROUTE: 0.0 , Meeter_Greeter;

$79 \$ \quad$ COUNT: Nogreet, 1 ; 
$5 \$$

$105 \$$

$15 \$$

$93 \$$
STATION, ASSIGN : QUEUE，

Timein_tria $94 \$$

Triage: goingtowait=uniform $(15,45)$; TriageQ:MARK (Timein_Triage); SCAN : Tnow-

Timein_triage.gt.goingtowait,109\$, Yes:

$\begin{array}{lll}109 \$ & \text { COUNT: } & \text { Else, } 17 \$, Y e s ; \\ 108 \$ & \text { DISPOSE; } & \text { leavingTri, } ; ;\end{array}$

\section{$17 \$$}

$19 \$$

$24 \$$

$22 \$$

$23 \$$

$6 \$$

$107 \$$

$16 \$$

$98 \$$
SEIZE，

DELAY :

RELEASE :

TALLY :

ROUTE:
1:

triage_nurse, 1 ; uniform $(5,10,5)$; triage_nurse, 1 ; ptype $+\overline{3}$, int (Timein_Triage), 1 ; 0.0 , WaitingRoom_Registration;

Timein_Regist.gt.goingtowait.or.NR(1).1t.mr(1);

STATION, ASSIGN : QUEUE,
1,10 :

If. Tnow$99 \$$

BRANCH,

1,10 :

If, Tnow-

Timein_Regist.gt.goingtowait, 111\$, Yes:

WaitingRoom_Registration; going towait=uniform $(15,45)$; RegisQ:MARK (Timein_Regist); SCAN :
$111 \$$

$110 \$$

$18 \$$

$20 \$$

$21 \$$

$25 \$$

$26 \$$

$39 \$$

nr (RGBed)
COUNT:

DISPOSE :

SEIZE，

DELAY :

RELEASE :

TALLY:

QUEUE,

SCAN :

Else, 18\$, Yes;

leavingReg, 1;

1:

Reg_Clerk, 1;

expo $(10,6)$;

Reg_Clerk, 1;

ptype+6, int (Timein_Regist), 1;

WaitingQ:MARK (Timein_WR); $\mathrm{nr}$ (FTBed). It. mr (ftbed) .OR. Tnow-

$100 \$$

Timein_WR.gt.240,113\$, Yes:

BRANCH,

COUNT:

DISPOSE;

$113 \$$

$112 \$$

$52 \$$

$40 \$$

mr(ftbed), 41\$, Yes:
TALLY:

BRANCH, ptype+9, interval (TimeIn_WR), 1; 1,10:

If, $\mathrm{nr}$ (ftbed) .1.t.

Else, 42\$, Yes; 
$7 \$$

$10 \$$

$11 \$$

$12 \$$

$8 \$$

$9 \$$

$13 \$$

$14 \$$

$43 \$$

$48 \$$

$44 \$$

$45 \$$

$46 \$$

$47 \$$

$49 \$$

$27 \$$

$28 \$$

$31 \$$

$32 \$$

$33 \$$

$29 \$$

$30 \$$

$34 \$$

$35 \$$

$50 \$$

$57 \$$

$53 \$$

$54 \$$

$55 \$$

$56 \$$

$58 \$$

$84 \$$

$59 \$$
STATION, QUEUE, SEIZE,

QUEUE, SEIZE,

DELAY :

QUEUE,

SEIZE,

DELAY:

RELEASE :

ROUTE:

STATION,

DELAY :

RELEASE :

TALLY :

DISPOSE;

STATION, QUEUE, SEIZE,

QUEUE, SEIZE,

DELAY :

QUEUE, SEIZE,

DELAY :

RELEASE :

ROUTE:

STATION, DELAY :

RELEASE :

TALLY :

DISPOSE;

CREATE,

DELAY :

ASSIGN :
RegularBeds;

RGBQ:MARK (Timein_RGBed) ;

1:

RGBed, 1 ;

NursesQ:

1:

Nurses, 1;

nurseT;

DOCQ ;

1:

Doctors, 1 ;

DrT:

Doctors, 1:

Nurses, 1;

0.0 , Recovery_for_RGB;

Recovery_for_RGB;

ed (ptype+12);

RGBed, 1 ;

ptype, int (Time_ER), 1;

FastTrack;

FTBedQ:MARK (Timein_FTBed) ;

1:

FTBed, 1;

NursesQ;

1:

Nurses, 1;

nurseT;

DOCQ;

1:

Doctors, 1;

DrT;

Doctors, 1:

Nurses, 1;

0.0 , Recovery_for_FTB;

Recovery_for_FTB;

ed (ptype+12);

FTBed, 1;

ptype, int (Time_ER), 1;

$1,0: 1,1$;

360 ;

$\mathrm{vble}=.478$ :

enter patients $=2$ : 


$\begin{array}{lll} & & \text { period }=2 ; \\ 85 \$ & \text { DELAY: } & 1080 ; \\ 86 \$ & \text { ASSIGN: } & \text { vble }=1: \\ & \text { enter_patients }=1: \\ & \text { period=1:NEXT }(84 \$) ;\end{array}$

$\begin{array}{lll}66 \$ & \text { STATION, } & \text { Meeter_Greeter } ; \\ 60 \$ & \text { QUEUE, } & \text { MeetGreetQ:MARK (Timeat_meet); } \\ 95 \$ & \text { SCAN: }\end{array}$

Timeat_meet.gt.goingtowait.or.NR(7).1t.mr (7);

96\$ BRANCH, 1,10:

Timeat_meet.gt.goingtowait, $106 \$$, Yes:

$$
\text { If, Tnow- }
$$

$\begin{array}{ll}106 \$ & \text { COUNT: } \\ 97 \$ & \text { DISPOSE; }\end{array}$

Else, 61\$, Yes;

leavingGreet, 1 ;

61\$ SEIZE, 1

$\begin{array}{lll}62 \$ & \text { DELAY: } & \text { Triangular }(.5, .85,1,7) ; \\ 63 \$ & \text { RELEASE: } & \text { Greeter, } 1 ; \\ 64 \$ & \text { TALLY: } & \text { ptype+12, int (Timeat_meet), } ; \\ 67 \$ & \text { ROUTE: } & 0.0, \text { Triage; }\end{array}$

$\begin{array}{lll}69 \$ & \text { STATION, } & \text { RushForBed; } \\ 104 \$ & \text { BRANCH, } & 1,10:\end{array}$

If, NR(RushBed) . It.MR (RushBed) .and.NR(5) . It.MR (5) . and.NR (6) . It.MR( 6), rbql, Yes:

rbql

RushBedQ:MARK (Timein_Rush) :DETACH ;

MATCH, : rbql, help1:

nql, goagain:

help1 SEIZE, dql, goagain2;

1:

Rushbed, 1:

Doctors, 1 :

Nurses, 1 ;

$70 \$$

$71 \$$

DELAY :

RELEASE :

$82 \$$

$81 \$$

$83 \$$

$73 \$$

$72 \$$

goagain

$90 \$$

nq1

goagain2

$103 \$$

dql
QUEUE,

SCAN :

RELEASE :

TALLY:

ROUTE:

DELAY :

SCAN :

QUEUE,

DELAY :

SCAN :

QUEUE,
DrRushT;

Doctors, 1 :

Nurses, 1:

rushtorege;

nr (RGBed). 1t. mr (RGBed);

RushBed, 1;

ptype+25, int (timein_rush), 1;

0.0 , RegularBeds;

1 ;

NQ (10).gt. 0.and.NR (5) . It.MR (5); dummynurseQ, 1:DETACH;

$1 ;$

NQ (10).gt. 0.and.NR (6) .1t.MR (6); dummydocQ, 1 :DETACH; 
$89 \$$

CREATE,

$102 \$$
CREATE,
1,.001:1,1:NEXT (90\$)；

1,.001:1, 1:NEXT (103\$); 


\section{Experimental Frame}

ATTRIBUTES: 1, ptype:

2, Timein_Regist:

3, Timein_Triage:

4, Timein_WR:

5, Time_ER:

6, DrT:

7, Timein_RGBed:

8, NurseT:

9, Timein_FTBed:

10, timeat_meet:

11,Timein_Rush:

12, DrRushT:

14, goingtowait;

VARIABLES: 1 , vble, 1 :

2, enter_patients, 1:

3, MaxRate, .1947:

4, period, 1:

5, ArrivalRate (2), .1157, .1947;

QUEUES: $\quad$ 1, RegisQ, FirstInFirstout:

2, TriageQ, FirstinFirstout:

3, WaitingQ, LowValueFirst (ptype):

4, RGBQ, LowValueFirst (ptype), shared:

5, FTBedQ, Firstinfirstout:

6, NursesQ, LowValueFirst (ptype), shared:

7, DocQ, LowValueFirst (ptype), shared:

8, dummyq, First InFirstout:

9, MeetGreetQ, FirstInFirstout:

10, RushBedQ, FirstInFirstout:

11, rushtoregQ, Firstinfirstout:

12, dummynurseQ, FirstinFirstout:

13, dummydocQ, FirstInFirstout;

RESOURCES: $\quad$ 1,Reg_Clerk,Capacity (1, ), -, Stationary:

2, triage_nurse, Capacity $(1),$,- , Stationary:

3, RGBed, Capacity $(15,1),-$, stationary:

4, FTBed, Capacity (5,), -, Stationary:

5, Nurses, Capacity $(10$,$) , -, Stationary:$

6, Doctors, Capacity $(5$,$) , - , Stationary:$

7, Greeter, Capacity $(1),$,- , stationary:

8, RushBed, Capacity (1,), - , Stationary;

STATIONS: $\quad 1$,Triage:

2, WaitingRoom_Registration:

3, RegularBeds:

4, FastTrack:

5, Recovery_for_RGB:

6, Recovery_for_FTB:

7, Meeter_Greeter:

8, RushForBed; 
COUNTERS: $\quad 1$, expo_dist, , Replicate:

2, gamma_dist, , Replicate:

3, AnotherHospital, , Replicate:

4, In of Type 1, Replicate:

5, In of Type 2, Replicate:

6, In of Type 3, Replicate:

7, In of Type 4, Replicate:

8, In of Type 5, Replicate:

9, InRush Type1, Replicate:

10, InRush_Type2, , Replicate:

11, rest, , Replicate:

12, willgreet, , Replicate:

13, NOgreet, , Replicate:

14, NoEntry, , Replicate:

15, leavingGreet, , Replicate:

16, leavingTri, , Replicate:

17, leavingReg, , Replicate:

18, LeavingWR, , Replicate;

TALLIES: $\quad$ 1,T_sys1, "tsys1.dat" :

2, T_sys2, "tsys2. dat":

3,T_sys3, "tsys3.dat":

4,T_sys4, "tsys 4. dat" :

5, T_sys5, "tsys5. dat" :

6, Time_Tri_P3:

7, Time_Tri_P4:

8,Time_Tri_P5:

9, Time_Reg_P3:

10, Time_Reg_P4:

11, Time_Reg_P5:

12, Time_Waiting_P3:

13, Time_Waiting_P4:

14, Time_Waiting_P5:

15, time_greet_p3:

16, time_greet_p4:

17, time_greet_p5:

26, Timein_Rush_P1:

27, Timein_Rush_P2 ;

DSTATS:

1,NR (1)/MR (1), Regis_Clerk_util:

2,NR (2)/MR (2), Triage_Nurse_uti1:

3, NQ (1), Avg_\#_RegisQ:

4, NQ (2), Aver_\#_TriageQ:

5,NQ (3),Avg_\#_WaitQ:

6, NQ (4), \#_RGBedQ:

7, NQ (5), \#_FTBedQ:

8,NR (3), \#_RGBedsBusy:

9, NR (4), \#_FTBedBusy:

10,NR(5)/MR (5), Nurse_Uti1:

11,NR (6)/MR(6), Doc_Util:

12,NR (3)/MR (3), RGBed_Util:

13, NQ (6), \#inNursesQ:

14, NQ (7), \#inDocQ:

15, NQ (10), \#inrushbedQ:

16, NQ (9), \#inMeetQ:

17 , NR (7), busyGreeter: 
18, NR (8), BusyRushBed;

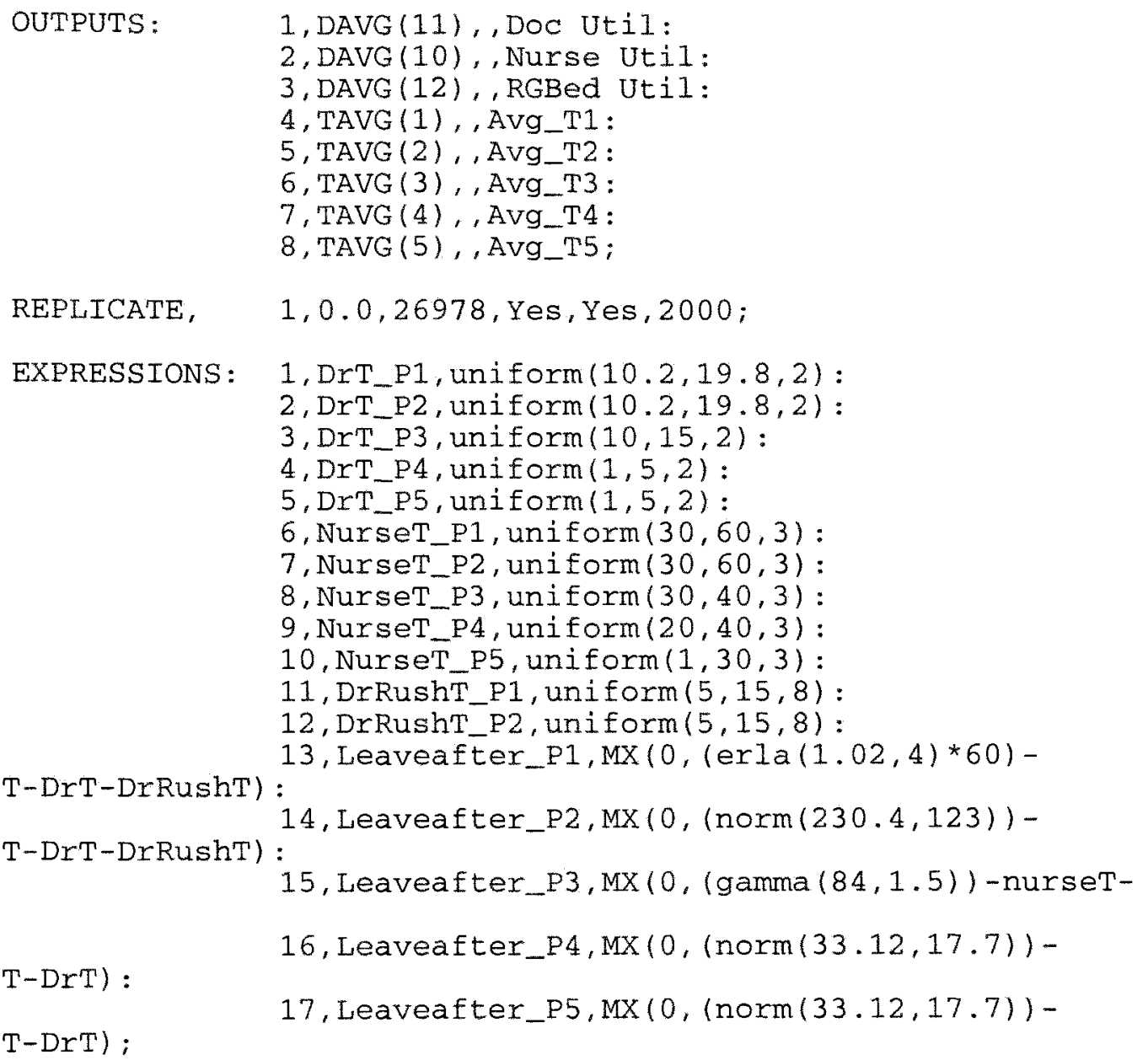




\begin{abstract}
APPENDIX C
This appendix shows the regression lines and the test of significance for each of the factors for the first iteration of the DOE experiment. Once the most significant factor (nurses) was determined and removed a second iteration was performed to the determine the second most significant factor (doctors). Now doctors and nurses are removed, leaving fast track and regular beds for analysis. However, since the results of the investigation determined that only doctors and nurses were to be used for further investigation in RSM, the last set of graph in this appendix were not used. However, they were kept for future work.
\end{abstract}




\section{APPENDIX D}

This appendix shows the results of the full factorial ANOVA Table of the two significant factors, nurses and doctors. 
$5 \times 5$ Full Factorial ANOVA Table for Tsys 2

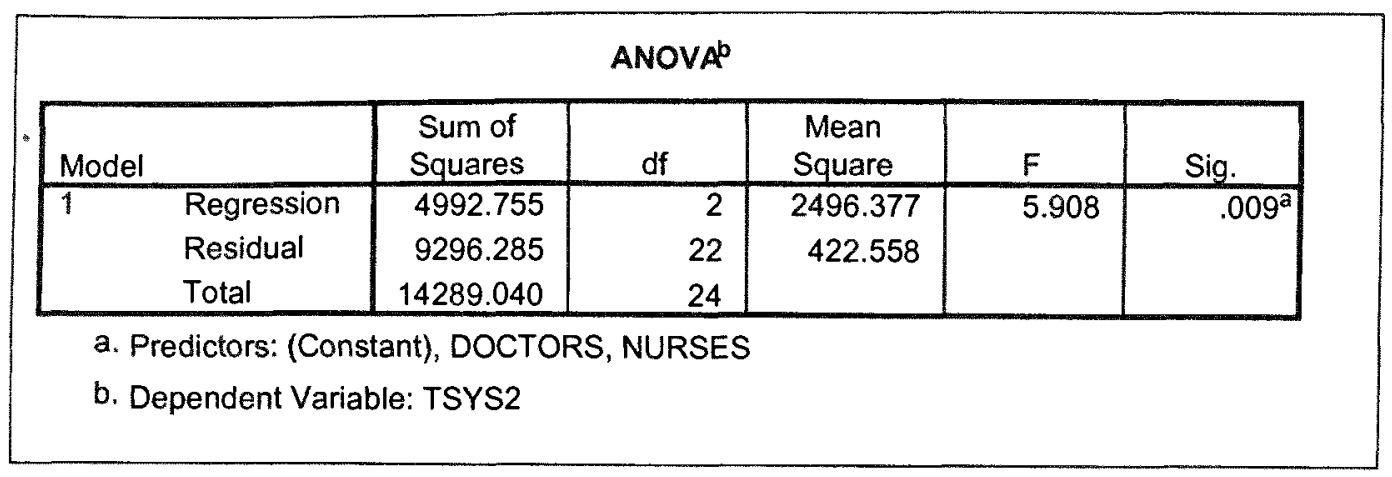

\begin{tabular}{|c|c|c|c|c|c|}
\hline \multicolumn{6}{|c|}{ Coefficients $^{a}$} \\
\hline \multirow[b]{2}{*}{ Model } & \multicolumn{2}{|c|}{$\begin{array}{l}\text { Unstandardized } \\
\text { Coefficients }\end{array}$} & \multirow[t]{2}{*}{$\begin{array}{c}\begin{array}{c}\text { Standardi } \\
\text { zed }\end{array} \\
\begin{array}{c}\text { Coefficien } \\
\text { ts }\end{array} \\
\text { Beta }\end{array}$} & \multirow[b]{2}{*}{$t$} & \multirow[b]{2}{*}{ Sig. } \\
\hline & $\mathrm{B}$ & Std. Error & & & \\
\hline (Constant) & 199.566 & 13.552 & & 14.726 & .000 \\
\hline NURSES & 2.621 & 1.359 & .337 & 1.929 & .067 \\
\hline DOCTORS & 9.298 & 3.802 & .428 & 2.446 & .023 \\
\hline
\end{tabular}


$5 \times 5$ Full Factorial ANOVA Table for Tsys 4

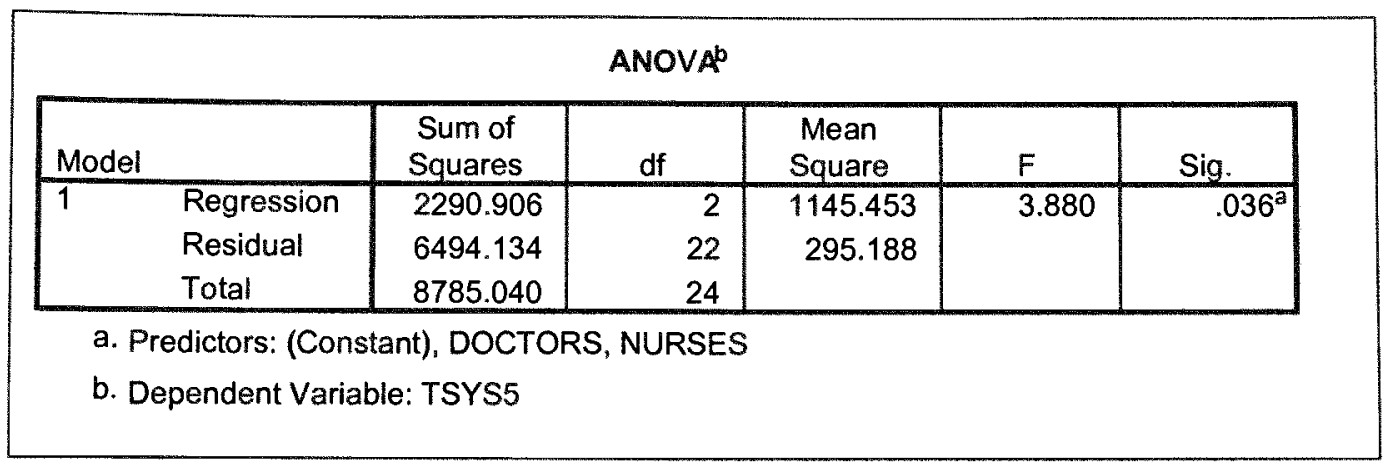

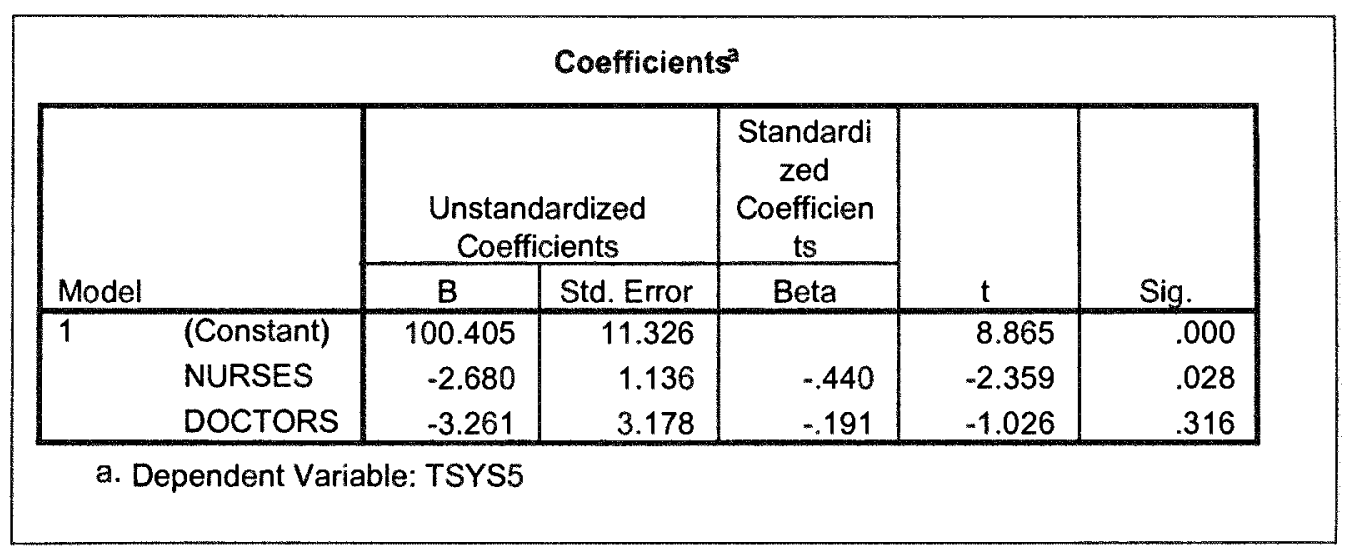


$5 \times 5$ Full Factorial ANOVA Table for Tsys 5

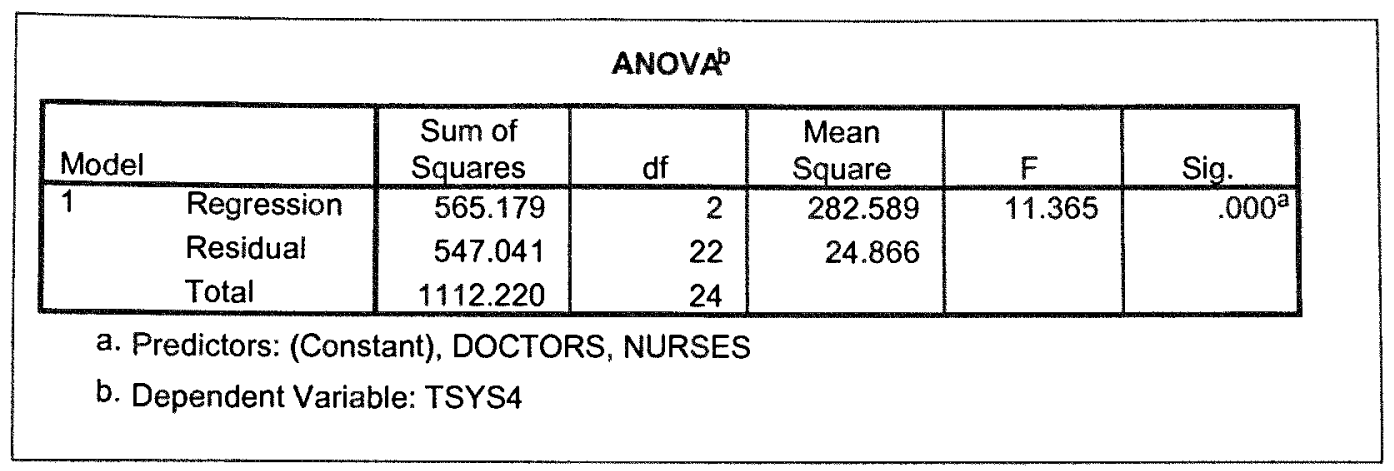

\begin{tabular}{|c|c|c|c|c|c|}
\hline \multicolumn{6}{|c|}{ Coefficients $^{\mathrm{a}}$} \\
\hline \multirow[b]{2}{*}{ Model } & \multicolumn{2}{|c|}{$\begin{array}{c}\text { Unstandardized } \\
\text { Coefficients }\end{array}$} & \multirow{2}{*}{$\begin{array}{c}\begin{array}{c}\text { Standardi } \\
\text { zed } \\
\text { Coefficien } \\
\text { ts }\end{array} \\
\text { Beta }\end{array}$} & \multirow[b]{2}{*}{$\mathrm{t}$} & \multirow[b]{2}{*}{ Sig. } \\
\hline & B & Std. Error & & & \\
\hline (Constant) & 84.846 & 3.287 & & 25.810 & .000 \\
\hline NURSES & -1.162 & .330 & -.536 & -3.523 & .002 \\
\hline DOCTORS & -2.320 & .922 & -.382 & -2.515 & .020 \\
\hline
\end{tabular}

